\title{
Project Report on Development of a Safeguards Approach for Pyroprocessing
}

\author{
Robert Bean
}

September 2010

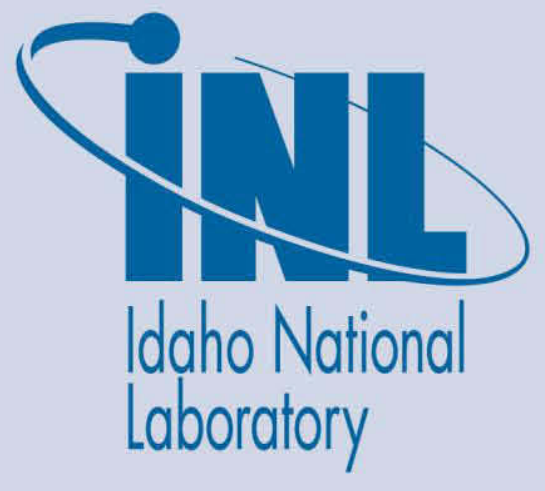

The INL is a U.S. Department of Energy National Laboratory operated by Battelle Energy Alliance 
INL/EXT-10-20057

\title{
Project Report on Development of a Safeguards Approach for Pyroprocessing
}

\author{
Robert Bean
}

September 2010

\author{
Idaho National Laboratory \\ Nuclear Nonproliferation Division \\ Idaho Falls, Idaho 83415 \\ http://www.inl.gov \\ Prepared for the \\ U.S. Department of Energy \\ Through the INL LDRD Program \\ Under DOE Idaho Operations Office \\ Contract DE-AC07-05ID14517
}




\section{DISCLAIMER}

This information was prepared as an account of work sponsored by an agency of the U.S. Government. Neither the U.S. Government nor any agency thereof, nor any of their employees, makes any warranty, expressed or implied, or assumes any legal liability or responsibility for the accuracy, completeness, or usefulness, of any information, apparatus, product, or process disclosed, or represents that its use would not infringe privately owned rights. References herein to any specific commercial product, process, or service by trade name, trade mark, manufacturer, or otherwise, does not necessarily constitute or imply its endorsement, recommendation, or favoring by the U.S. Government or any agency thereof. The views and opinions of authors expressed herein do not necessarily state or reflect those of the U.S. Government or any agency thereof. 



\begin{abstract}
The Idaho National Laboratory has undertaken an effort to develop a standard safeguards approach for international commercial pyroprocessing facilities. This report details progress for the fiscal year 2010 effort. A component by component diversion pathway analysis has been performed, and has led to insight on the mitigation needs and equipment development needed for a valid safeguards approach. The effort to develop an in-hot cell detection capability led to the digital cloud chamber, and more importantly, the significant potential scientific breakthrough of the inverse spectroscopy algorithm, including the ability to identify energy and spatial location of gamma ray emitting sources with a single, non-complex, stationary radiation detector system. Curium measurements were performed on historical and current samples at the FCF to attempt to determine the utility of using gross neutron counting for accountancy measurements. A solid cost estimate of equipment installation at FCF has been developed to guide proposals and cost allocations to use FCF as a test bed for safeguards measurement demonstrations. A combined MATLAB and MCNPX model has been developed to perform detector placement calculations around the electrorefiner. Early harvesting has occurred wherein the project team has been requested to provide pyroprocessing technology and safeguards short courses.
\end{abstract}




\section{ACKNOWLEDGEMENTS}

The author would like to acknowledge the vital contributions of others throughout the project. Richard Metcalf, as the co-Principal Investigator, directed much of the effort. David Gerts and his team (Terri Knudsen, Marc Paff, Hugh Wimberly, Nathan Fredette, Warren Jones, Alan Mecham) who developed the inverse spectroscopy algorithm and designed the digital cloud chamber. Michael Simpson, Guy Fredrickson, Dee Vaden, Steve Hermann, Greg Teske, Tom Johnson, and Ken Marsden from the Pyroprocessing Technology group provided pyroprocessing expertise for the diversion pathway discussions, and Chuck Solbrig provided excellent review of the progress. Alice Tomanin started the MCNP modeling effort and obtained the first results. James West combined the previous and current diversion pathway discussions. Finally, Brian Castle and Sean Morrell coordinated the equipment installation study. Others work with us as well, and their contributions are appreciated. 


\section{CONTENTS}

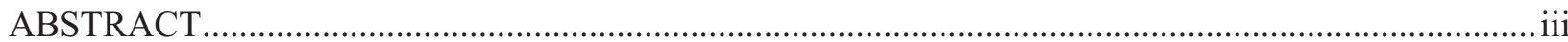

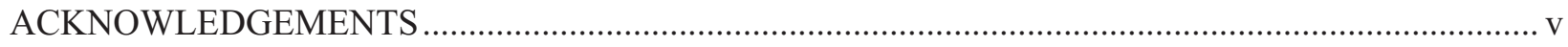

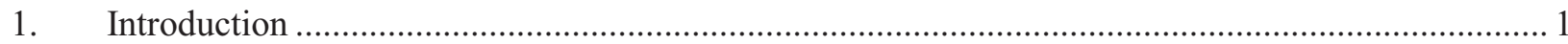

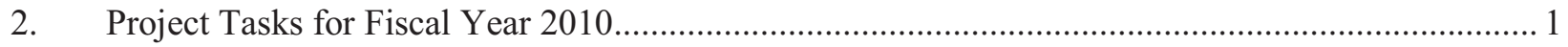

2.1 Diversion Pathway Analysis ........................................................................................ 2

2.2 Digital Cloud Chamber and Inverse Spectroscopy Algorithm Development ........................ 2

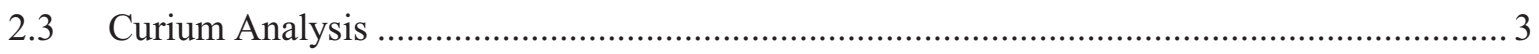

2.4 Investigation of Installation of Safeguards Monitoring Equipment .................................... 4

2.4.1 Installation in the Fuel Conditioning Facility .......................................................... 4

2.4.2 Investigation of Detector Placement ...................................................................... 4

2.5 Goals Driven Safeguards Visualization ....................................................................... 4

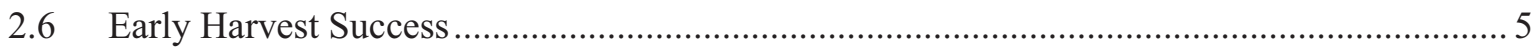

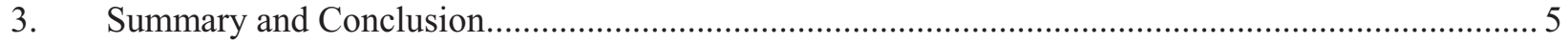

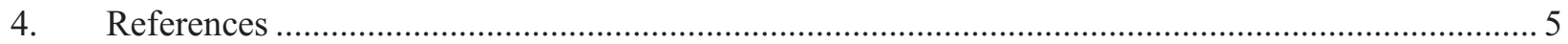

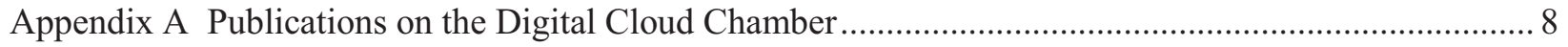

Appendix B Analysis of Fuel and Salt Samples for Curium …..........................................................2

Appendix C Technical Evaluation for Safeguards Equipment Installation .......................................... 30 


\section{Project Report on Development of a Safeguards Approach for Pyroprocessing}

\section{Introduction}

Large-scale investment in pyroprocessing facilities will only become acceptable if comprehensive safeguards are established to meet the International Atomic Energy Agency's (IAEA) standards for detecting the diversion of significant quantities of nuclear material in a timely manner. Without these safeguards, proliferation concerns will impede the commercial adoption of pyroprocessing and limit the development and expansion of fast reactor technology.

The primary objectives of this laboratory-directed research and development (LDRD) project are to determine the validity of existing safeguards approaches for pyroprocessing facilities and exploit the unique attributes of the pyroprocess to identify new safeguards methods. Idaho National Laboratory's (INL) development of these pyroprocessing safeguards will constitute a new sub-field in reprocessing safeguards and therefore will bring INL recognition as the preeminent experts in international safeguards applied to pyroprocessing facilities. INL's unique pyroprocessing facilities create an ideal opportunity to take the lead on this topic.

The present-day lack of an agreed upon comprehensive safeguards approach that can meet the IAEA goal quantity and timeliness criteria for pyroprocessing facilities is the fundamental driver of this project. Without it, the IAEA is unable to determine that the state is in compliance with its treaty obligations for peaceful use of the nuclear material. The National Nuclear Security Administration's (NNSA) Next Generation Safeguards Initiative (NGSI) contains a requirement to develop a safeguards approach for Pyroprocessing facilities.

Many countries have expressed interest in pursuing pyroprocessing research. South Korea has an active research and development program, India has stated that pyroprocessing is the preferred method of processing their fast reactor fuel, and Japan is performing pyroprocessing research. [1] Development of a safeguards approach that can verify the nuclear material accountability of these expected programs and facilities is crucial.

The goal of this project is to develop a viable safeguards approach for pyroprocessing facilities that, using the INL FCF as a scientific and experimental baseline, can be applied to proposed commercial scale international facilities.

\section{Project Tasks for Fiscal Year 2010}

Efforts in Fiscal Year (FY) 2010 were undertaken to continue those begun in FY 2009. Specifically, the project effort was directed towards

- Continuation and advancement of the diversion pathway analysis

- Design and fabrication of the digital cloud chamber and further development of the inverse spectroscopy algorithm 
- Laboratory analysis of the Curium content of selected fuel samples from the INL pyroprocessing facility

- Investigation of the installation of IAEA safeguards equipment at the INL Fuel Conditioning Facility (FCF)

- Investigation of the application of goals driven safeguards principles to pyroprocessing

Additionally, effort was begun to perform

- MCNP modeling of detector response around the electrorefiner

The project also worked with the INL classification officer to develop a project classification aid that drew from multiple classification guidance sources.

\subsection{Diversion Pathway Analysis}

The diversion pathway analysis from FY 2009 was continued. Again, safeguards experts met with pyroprocessing experts to investigate potential actions and activities that would lead to the diversion of nuclear material out of the normal material flow pathway. The potential diversion pathways have been combined with the results from the FY 2009 effort and are described in INL/LTD-10-20069. [2]

The primary conclusion thus far from the diversion pathway analysis is that due to the complexity of the pyroprocessing steps (i.e. constant addition of reagents, and in a commercial facility the constant movement of salt for recycle) there are many opportunities to alter the process such that nuclear material is diverted from the expected pathway to elsewhere in the process. However, each identified potential diversion pathway required 'abnormal' operation such as adding the incorrect reagent, running a process step longer or shorter than normal, non-standard movement of materials and manipulator arms, or outright fraud such as designing a hidden cathode to covertly collect material. Accordingly, each has an identified mitigation. It should be noted that not all potential diversion pathways have been experimentally verified as realistic, or even possible. Similarly, the proposed mitigation actions also have not yet been verified experimentally.

\subsection{Digital Cloud Chamber and Inverse Spectroscopy Algorithm Development}

Many of the potential diversion pathways identified during the FY 2009 diversion pathway analysis were enabled by 'adjusting' the contents of a container to redistribute the $\mathrm{Pu}$ in a non-homogenous fashion (i.e., settled out on the bottom). Additionally, many nondestructive assay (NDA) techniques require a homogeneous, or near-homogeneous, distribution of the material to be measured, or at least some knowledge of the distribution to reduce uncertainty in the measurement. In either case, the ability to measure, via NDA and from within the hot cell environment (high temperature, difficult to access for maintenance, high radiation fields), the distribution of the nuclear material in a container would be extremely useful.

A digital cloud chamber (DCC) was proposed. [3]. A cloud chamber is a mechanical device, therefore largely impervious to elevated temperature and radiation exposure. Coupling the cloud chamber with digital cameras for the data acquisition allows the use of fiber optics to distance the sensitive electronics from the hot cell interior environment. The development of an inverse spectroscopy algorithm that can determine the energy and originating spatial location of the incident radiation was the final piece. A DCC will be able to readily determine if the Pu content of a container, such as a salt barrel in the hot cell, is homogeneously distributed. Depending on the final energy and spatial resolution that can be 
achieved, the DCC may even be able to perform accountancy measurements for the operator or verification of accountancy measurements for the IAEA.

The inverse algorithm was fully developed for gamma interactions, where an incident gamma interacts with the DCC working fluid via photoelectric, Compton scatter, or pair production reactions. The algorithm was coded to run on a graphical processing unit and sample particle tracks were generated to demonstrate proof of concept for the calculations. A prototype DCC was designed and fabricated to allow proof of principle measurements. The prototype has been delivered to the INL and is ready for assembly and data collection.

The potential to determine the energy and spatial location of a gamma ray source with a single, stationary, non-complex radiation detection system represents a major scientific breakthrough. It is vital that this effort receives appropriate follow through.

Two papers and a poster were presented at the Institute of Nuclear Materials Management (INMM) Annual Meeting in Baltimore, MD, July 11-15, 2010. The full papers are included in Appendix A. The INL has declared its intent to pursue a software copyright for the programming developed this year. The algorithm development related to extracting the source gamma ray energy from a Compton scattering event has been submitted as an IDR to the INL Best committee. Additionally, a proposal was submitted to NNSA/NA-22 to apply the spatial imaging potential of the DCC to treaty verification activities involving warhead counting. Finally, a journal article related to the application of this methodology to neutron spectroscopy, "Efficient and Accurate Computation of Elastic Cross Sections in the Single-Level Breit-Wigner Resonance Region," has been written and is in process for submission to Nuclear Science and Engineering.

\subsection{Curium Analysis}

A previously proposed safeguards approach for pyroprocessing [4] suggested the use of gross neutron counting to track the movement of plutonium bearing material through the facility and processes. Spent nuclear fuel (especially lower enriched and higher burnup), however, also contains Curium, whose isotopes are also significant neutron emitters. Accordingly, a gross neutron count of spent nuclear fuel is counting mostly $\mathrm{Cm}$, and not $\mathrm{Pu}$ exclusively. If the $\mathrm{Cm}$ transfers with the $\mathrm{Pu}$ throughout the process, a careful (via destructive analysis) measurement of the $\mathrm{Pu} / \mathrm{Cm}$ ratio at the outset could then be used to calculate the $\mathrm{Pu}$ contribution to the gross neutron count. Thus neutron counting could serve to track $\mathrm{Pu}$ movement and perform $\mathrm{Pu}$ accountability measurements.

Preliminary analysis in FY 2009 determined that it was unclear that the Cm would completely transfer with the $\mathrm{Pu}$ in a pyroprocessing facility. [2] Specifically, while the electro-potential of $\mathrm{Cm}$ and $\mathrm{Pu}$ are close, they are not equal. While not yet experimentally verified, it should be possible (either intentionally or inadvertently) to operate the electrorefiner such that one, and not the other, is deposited on the cathode.

At the end of FY 2009, a Cm standard was purchased to allow the INL analytical laboratory to add $\mathrm{Cm}$ to their suite of isotopic and elemental measurements. Curium measurements were performed on one of the Experimental Fast Breeder Reactor II (EBR-II) blanket element batches. A previously processed batch of light water reactor fuel, from which salt samples had been saved, was also measured. A description of the $\mathrm{Cm}$ measurements and results is given in Appendix B. Unfortunately, the results were inconclusive, as the $\mathrm{Cm}$ was below detectable levels in the processed salts.

The use of gross neutron counting, combined with knowledge of the $\mathrm{Pu} / \mathrm{Cm}$ ratio was not discredited, but the difficulty of obtaining a useable $\mathrm{Cm}$ measurement was clearly demonstrated. 


\subsection{Investigation of Installation of Safeguards Monitoring Equipment}

Part of the development of a standard safeguards approach that can be agreed to by multiple parties (e.g. host States and the IAEA) is the selection of the necessary equipment and the determination of appropriate locations, such as key measurement points, critical material collection or pathway points and the like for the placement of the instruments. Additionally, it must be satisfactorily demonstrated that the instruments will collect the proper signal (video, gamma or neutron measurement, etc.) and that it can verify the safeguarded activity.

\subsubsection{Installation in the Fuel Conditioning Facility}

The effort in FY 2009 developed an equipment list of the typical measurement and monitoring equipment employed by the IAEA, and a discussion of some of the installation requirements. [2]. For FY 2010, full installation in the INL FCF was investigated to determine the requirements involved in an active nuclear facility. This project requested a Technical Evaluation, which is included as Appendix C. [5] The Technical Evaluation looked at the issues and costs associated with placing a single camera where it could observe the transfer port between the air cell and the argon cell at the FCF. Additionally, the Nuclear Nonproliferation Division developed (independent of this project) a broad cost estimate for installation of a large number of cameras, radiation monitors, and their associated cabling and equipment cabinets. The Technical Evaluation was passed along to the team preparing the broad cost estimate to assist them.

Various alternatives were explored for the location and feedthrough (passing signal and power cabling through the hot cell wall). The recommended alternative would mount the camera up above the floor clutter to minimize the chances of bumping or blocking the camera. The estimated cost for engineering, equipment and installation labor was $\$ 215,000$.

\subsubsection{Investigation of Detector Placement}

An effort was undertaken to model an electrorefiner (based upon the Mark IV electrorefiner currently in use in FCF) using MCNP. Beginning with historical operational information about FCF operations, a MATLAB program was developed that would calculate the source term (gamma and neutron emission) from the processed fuel that remained within the electrorefiner. This source term was put into the MCNPX input to then allow calculation of the detector response of representative radiation detectors placed at various locations. Thus far, preliminary results have been obtained that indicate the MATLAB and MCNP models are working correctly, and that the detectors can detect the changing radiation intensity as fission products build up in the electrorefiner. The modeling effort is expected to be continued in FY 2011 to improve and optimize the detector models and placement.

\subsection{Goals Driven Safeguards Visualization}

It was decided to create a visualization of the INL FCF pyroprocessing facility to demonstrate Goals Driven Safeguards. Goals Driven Safeguards (GDS) is the idea of designing a safeguards system that focuses on the goal: Detection of an attempt to divert nuclear material that results in a significant quantity being diverted. [6] The safeguards does not have to expressly depend upon measurement of the nuclear material. In such a case, monitoring the activity to observe of the equipment usage, motions, timing, etc. correlate with normal processing (e.g. the material is accounted for because you have confidence in its location) or with abnormal operations (e.g. investigation is needed because material may have been misdirected). The project team met with a graphic visualization expert and laid out a plan for creating a 
visualization of this concept using FCF as a baseline and typical FCF operations as the template for normal operations. This task is ready to continue with the resumption of LDRD funding for FY 2011.

\subsection{Early Harvest Success}

The current increased global interest in pyroprocessing and pyroprocessing safeguards and nonproliferation issues has led to a demand to inform various government agencies about the technical aspects of pyroprocessing so that they can perform their assigned duties. A government agency has requested a short course for this purpose, and a second agency has declared their intent to follow suit when the new FY begins. The efforts in pyroprocessing safeguards under this project have positioned INL to be recognized as experts in this field.

A less tangible, but no less significant impact has been the cross training that occurred due to diversion pathway discussions. The pyroprocessing experts have clearly begun to understand and consider international safeguards, impacting their proposals and agreements, as well as the training offered to IAEA inspectors on pyroprocessing technology. Similarly, the safeguards experts have become well versed in pyroprocessing technology. As the parallel effort to develop training courses based around the FCF and IAEA safeguards equipment progresses, this cross training will be invaluable.

\section{Summary and Conclusion}

A component by component diversion pathway analysis has been performed, and has led to insight on the mitigation needs and equipment development needed for a valid safeguards approach. The effort to develop an in-hot cell detection capability led to the digital cloud chamber, and more importantly, the significant potential scientific breakthrough of the inverse spectroscopy algorithm, including the ability to identify energy and spatial location of gamma ray emitting sources with a single, non-complex, stationary radiation detector system. Curium measurements were performed on historical and current samples at the FCF to attempt to determine the utility of using gross neutron counting for accountancy measurements. A solid cost estimate of equipment installation at FCF has been developed to guide proposals and cost allocations to use FCF as a test bed for safeguards measurement demonstrations. A combined MATLAB and MCNPX model has been developed to perform detector placement calculations around the electrorefiner. Early harvesting has occurred wherein the project team has been requested to provide pyroprocessing technology and safeguards short courses.

A solid basis has been formed to develop a safeguards approach, using processing experience at FCF

as a baseline and demonstration platform, that can be applied to international commercial pyroprocessing facilities.

\section{References}

1. Inoue, T., Koch, L. Development of Pyroprocessing and its Future Direction. Nucl. Eng. And Tech. Vol. 40, No. 3, p. 183-190, 2008.

2. West, J. et al. Diversion Scenarios and Mitigation Techniques for a Pyroprocessing Safeguards Approach. Idaho National Laboratory Report, INL/LTD-10-20069, Rev 0., Oct. 2010.

3. Bean, R. et al. Development of a Safeguards Approach for Pyroprocessing. Idaho National Laboratory Report, INL/LTD-09-16970, Rev. 0, Sept. 2009.

4. Kim, T.H. et. al. Safeguards Systems for the Advanced Spent Fuel Conditioning Process Facility. Proceedings of Global 2007, Boise, ID, 2007. 
5. IAEA Equipment Installation. Idaho National Laboratory Technical Evaluation Study, TEV-916, Rev. 0 Aug. 31, 2010.

6. Wigeland, et. al. The Concept of Goals Driven Safeguards. Idaho National Laboratory Report, INL/EXT-09-15511, Feb. 2009. 


\section{Appendix A}

\section{Publications on the Digital Cloud Chamber}

The following two papers were presented at the INMM annual meeting held in Baltimore, MD, July 1115, 2010. Additionally, a poster, "Using GPU Programming for Inverse Spectroscopy," was presented at the same INMM meeting. 


\title{
Nuclear Material Accountability Applications of a Continuous Energy and Direction Gamma Ray Detector
}

\author{
David Gerts, Marc Paff, Robert Bean \\ Idaho National Laboratory \\ P.O. Box 1625, Idaho Falls, ID 83415
}

\section{Abstract:}

The Idaho National Laboratory has recently developed a detector system based on the principle of a Wilson cloud chamber that gives the original energy and direction to a gamma ray source. This detector has continuous energy resolution and the direction to the source can be resolved to desired fidelity. Furthermore, the detector has low power requirements, is durable, operates in widely varying environments, and is relatively inexpensive to produce. This detector is expected, however, to require significant measurement time. Advantageously, because of the use of compressed air, the detector is expected to scale to very large sizes with a linear increase in cost. The proof of principle detector has an active region of $100,000 \mathrm{~cm}^{3}$. Applications of this detector are described in the context of nuclear material monitoring.

\section{Introduction}

Safeguards and treaty monitoring show some similarities in requirements for detectors -robust, low cost, and quantification/identification of nuclear materials. Idaho National Laboratory (INL) has recently initiated an internal research project that developed a radiation sensor suitable for the harsh environment of hot cell fuel monitoring. This sensor is based on the Wilson cloud chamber invented in 1895. Yet, a revolution in materials, imaging, and processing has occurred since the 1960 s when cloud chambers were abandoned in favor of solid state detectors.

Many radiation detectors have tremendous capability in laboratory conditions that do not translate well into a more general environment, such as safeguards. For example, high purity germanium detectors have excellent energy resolution for gamma rays, but require either liquid nitrogen or complex/power intensive cooling systems. Other detectors, such as CZT or Nal, have other excellent attributes but are insufficient to determine source type, intensity, and location. Furthermore, nearly all of these solid state designs have significant costs associated with scaling to large volumes.

INL is in the process of demonstrating that a cloud chamber can accurately describe radioactive sources in terms of the isotope, absolute intensity, and location (direction and distance) of unknown sources. This result is accomplished by a combination of a new inverse spectroscopy method based on evidential theory and innovative mechanical/digital design of the cloud chamber. 


\section{Proof of Principle Cloud Chamber Design}

The cloud chamber detector represents an alternative method of detecting radiation. The invention of the cloud chamber is attributed to the Scottish scientist Charles Thomas Rees Wilson who was studying how to recreate clouds in a laboratory setting early in the $20^{\text {th }}$ century. The cloud chamber itself is a sealed container filled with a supersaturated liquid/gas. Often this is water or alcohol vapor. It was soon discovered that cloud chambers were also a useful means of visualizing the paths traveled by radiation. As radiation particles, such as or particles travel through the vapor, they ionize the surrounding atoms. Gas molecules then condense around these ions, thus forming streaks of mist (Figure 1). The size, width and length of these streaks are indicative of the type of radiation particle and its energy [1].

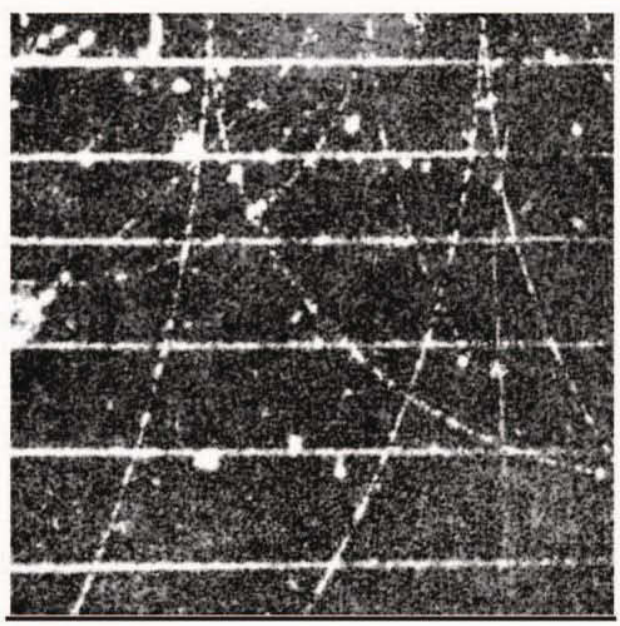

Figure 1: Radiation Tracks in a Cloud Chamber

The INL designed cloud chamber, schematic shown in Figure 2, has dimensions of 16 in. $x 16$ in. $x 24$ in. making for a 6000 in. $^{3}$ size (or $100,000 \mathrm{~cm}^{3}$ ). The four pistons shown provide sufficient volume to ensure that the chamber can be made supersaturated with a mixture of ethyl alcohol and water. Acetone was not chosen due to the corrosive potential for the plastic enclosure. The pistons have simple $110 \mathrm{~V} / 60 \mathrm{~Hz}$ power requirements. This means that the active chamber does not have any special power requirements. In addition, the chemicals require minimal special handling.

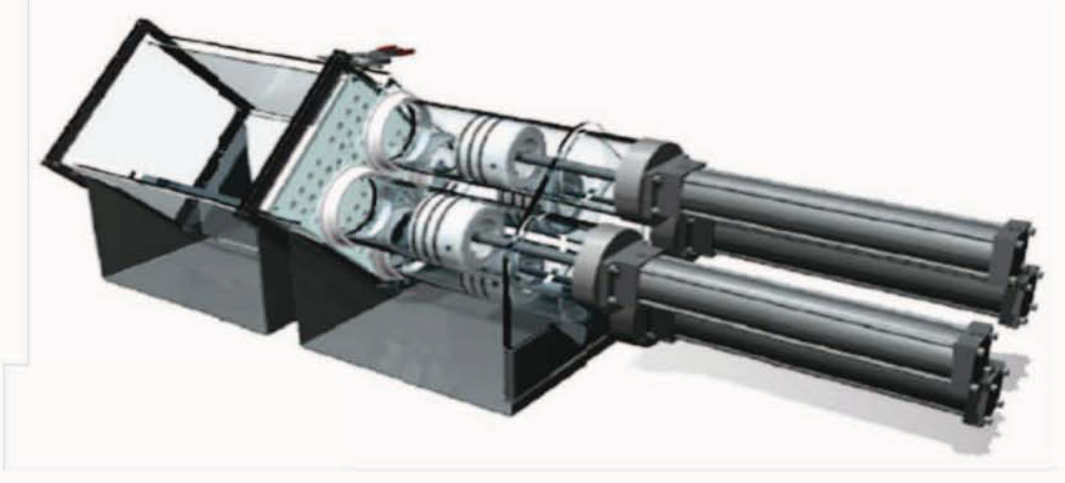

Figure 2: Large Active Volume Digital Cloud Chamber Design

Not shown in Figure 2 are the two orthogonally placed cameras to resolve the cloud chamber tracks in 3D. The cameras are connected using a high speed, such as firewire or USB 2.0, connection. The initial cameras have over 10 megapixel resolution with an approximately $1 \mathrm{~Hz}$ frame rate giving an excellent ability to resolve the droplet tracks, but not the formation of the droplets. For this application, 
this should be sufficient because the primary interest is resolving each pixel as finely as possible. With these two 10 megapixel cameras, there are nearly ten billion voxels giving a resolution of approximately $10 \mu \mathrm{m}$ in each dimension.

\section{Inverse Spectroscopy}

The inverse spectroscopy portion of this research has led to the conclusion that the detector can have effectively continuous energy and continuous direction for its results. This is primarily a result of having the electron energy and direction information. The combination of both of these allows for a very sophisticated reconstruction technique based on the Dempster-Shafer theory of evidence (or belief functions). The Dempster-Shafer theory is based around using the maximum amount of evidence in support of hypotheses [2]. It is a quantified theory which is ideal for random and uncertain information. In the case of the reconstruction in support of the cloud chamber, Dempster-Shafer theory allows for the understandably large degree of uncertainty as well as the fundamental random nature of nuclear radiation.

Fundamentally, the reconstruction algorithm can use any arbitrary number of hypothesis bins for the gamma ray source voxel and an equally arbitrary number of energy groups to resolve the solution to a desired level. Effectively, this means that as more data is gathered, the reconstruction algorithm consistently improves the solution. The solution is not unique, however. Instead, the data points to a most probable solution. In inverse spectroscopy, unique solutions occur only for a specialized class of problems (no scatter, perfect detector, unique sources...). This inverse spectroscopy approach avoids this problematic result of mathematics by simply weighing the possibility that a gamma ray source is located in a particular location. Other solutions might be correct, but, selecting the most likely solution (or several of the most likely solutions) is typically correct. Again, as more data becomes available, as in the case of a long term monitoring problem, the likely solutions collapse strongly into a recognizable solution.

\section{Applications}

The INL digital cloud chamber was initially designed in response to the first listed application for hot cell monitoring. Since that initial concept was developed, we have considered what other domains might be ripe for this detector. We consider that any applications might be appropriate which have the properties:

1. Not significantly time-constrained

2. Widely variable temperature requirements (from $-50^{\circ} \mathrm{C}$ to $400^{\circ} \mathrm{C}$ )

3. Need physically large detectors

4. Have interesting geometries

5. Operate in highly contaminated environments

6. Require accurate determination of isotopic constituents

In many cases, these requirements exactly fit with long term monitoring of nuclear material. We present a variety of cases below that have some or all of these properties.

\section{Hot Cell Monitoring}

The INL original application was for long term monitoring of nuclear material within a hot cell environment. This environment is highly contaminated and has temperatures approaching several hundred degrees Celsius. Because the application is based around monitoring for changes over months or years to nuclear material within the hot cell, INL was concerned about traditional nuclear detectors. In addition to the expected degradation due to the high temperatures, the radiation damage to typical 
detectors may result in poor performance. In addition, most detectors cannot resolve the location of the nuclear material which was a central requirement for this application.

The digital cloud chamber can make a long term measurement and continuously ascertain that the material has not been substituted or moved during the duration. The size of the chamber is considered a factor in the space-constrained hot cell. But, it was determined that space could be made available for this technology if it should be deployed.

\section{Spent Fuel Measurement}

The digital cloud chamber is an inherently radiation hardened detector system, as the chamber itself is simply a mechanical device, and the electronics can be removed to a safe distance via fiber optics for the cameras and lighting. Additionally, the large volume and low density of the working fluid will allow for a tremendous count rate before the charged particle trails cannot be resolved. Accordingly, a digital cloud chamber offers distinct advantages for the measurement and quantification of the plutonium content of spent nuclear fuel.

The gamma and neutron emissions from a spent fuel assembly will interact with the digital cloud chamber working fluid. A typical chamber will have cameras positioned to capture images of the droplet trails from multiple directions through fiber optic lenses and cables, allowing a 3-D reconstruction of the charged particle pathway, see Figure 3 . The chamber will be illuminated as needed, also by directing light through fiber optics. As described above, the energy and direction of the charged particle can be calculated, providing evidence to the algorithm about the probable interaction, source particle type and energy, and the direction from which it originated. Given sufficient counts, a calculation of the location and quantity of the plutonium in the spent fuel can be performed.
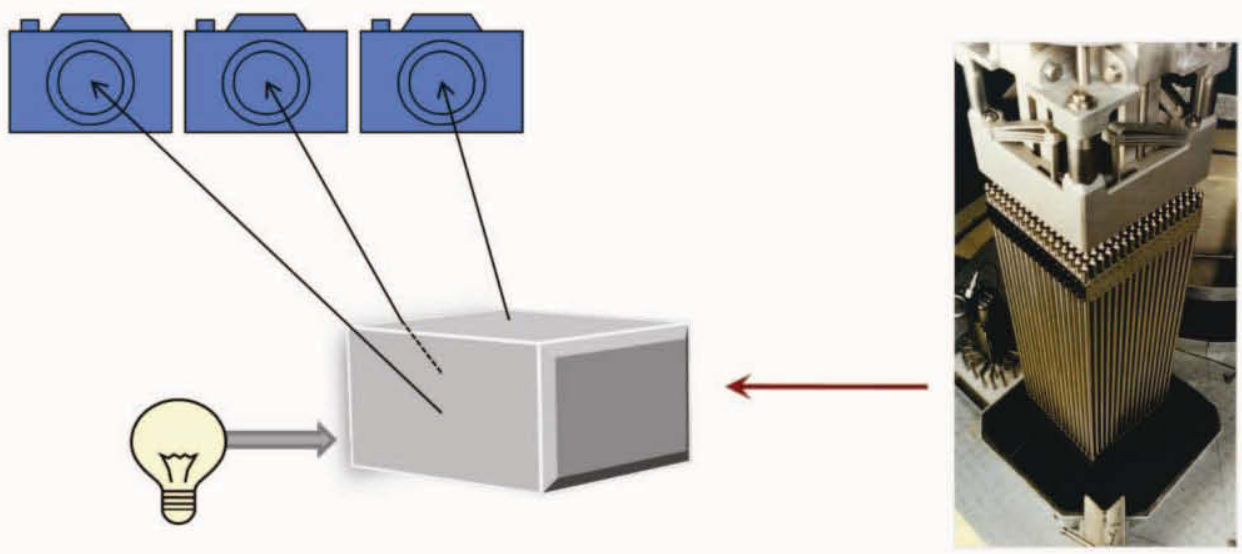

Photo Credit: French Nuclear Newsletter

Figure 3: Measurement of a fuel assembly using a digital cloud chamber

The digital cloud chamber in Figure 3 is represented as rectangular to demonstrate the 3-D camera configurations. In practice, however, the shape of the chamber is not limited to rectilinear boxes. Any geometry can be used given sufficient cameras to image the volume properly and a careful calibration of the resulting camera image. Further, the physical size of the digital cloud chamber is limited only by the mechanical requirements to maintain the working fluid conditions necessary for droplet formation. Accordingly, to increase the count rate further, the digital cloud chamber can be built in an annular fashion to surround the fuel element, see Figure 4. Such a chamber could also operate underwater, although with the added uncertainty caused by shielding and scattering in the water. 


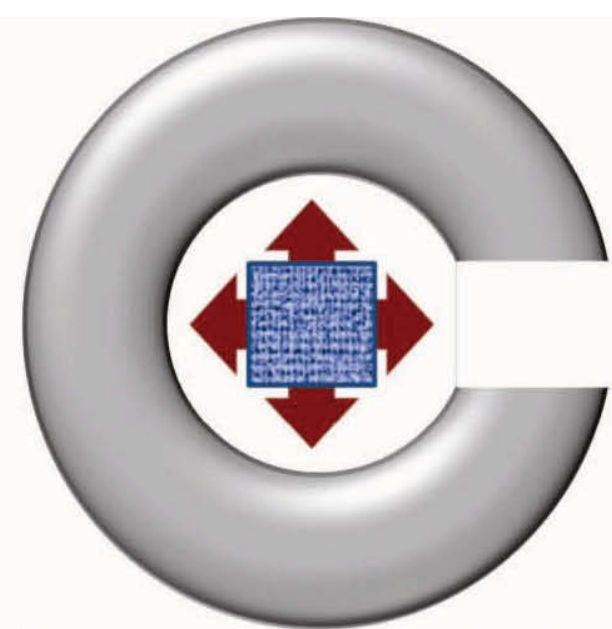

Figure 4: Measurement of a spent fuel assembly within an annular-shaped digital cloud chamber

\section{Safeguarding Large Areas with a Single Detector}

INL envisions using the digital cloud chamber for safeguarding large regions. One of the key features of a digital cloud chamber is that it can continuously monitor an area that could be filled with spent fuel or other safeguarded materials. Digital cloud chambers can also be scaled to very large volumes depending on the specific application. As shown in Figure 1, the initial digital cloud chamber has over a $100,000 \mathrm{~cm}^{3}$ active detection volume. INL envisions that future applications could include evaluating total plutonium masses and isotopic distributions in large areas such as spent fuel storage areas.

\section{Monitoring Dry Cask Storage}

In a typical monitoring application, it is often decided to observe the loading of spent fuel into dry cask storage, and then monitor the loaded cask for signs of movement or tampering rather than carefully measure the plutonium mass content within a given fuel assembly. This may be done for reasons of cost, time, or ability to accurately obtain the measurement. A simple large digital cloud chamber, or an array of such chambers, can be put in place within the dry cask storage facility to continuously monitor the spent nuclear fuel cask farm. The casks already massively shield the radiation emissions, drastically reducing the count rate in the chamber; however, the long monitoring time will overcome this limitation.

Given the detector measurements, a reconstruction algorithm develops dynamic images of the location and quantities of the nuclear material in the casks. These images become more refined as time passes. Changes in the fuel position, such as movement of a cask or removal of a fuel element from an opened cask, alters the image and flags the facility for follow-up inspector attention.

\section{Wide Area Monitoring for Nuclear Material}

The cloud chamber detector design being proposed addresses the need for a compact and mobile detector that law enforcement agencies, such as police departments, may use to detect the location and composition of nuclear material being stored or transported within the United States.

The concept of equipping police departments with radiation detectors is not a new concept. Heightened concerns after the events of 9/11 over a potential nuclear attack coupled with the realization that the police force patrols large swaths of major cities have led to the inception of nuclear detection programs within police departments. The New York Police Department (NYPD) has addressed this issue on multiple fronts. In 2009, the NYPD began a three pronged approach. Approximately 8,000 
dosimeters were purchased and are worn by officers to detect hot spots of radiation. Additionally, the NYPD uses a portable Thermo-Fission Portal Monitor $(\sim 100,000)$ at the main entrances to large events in New York City, such as major sporting events or political events. Also, the Department of Homeland Security gave the NYPD three Advanced Spectroscopic Portal Monitors $(\sim \$ 450,000)$ originally intended for a port application. These monitors were installed within large sports utility vehicles in order to monitor entrances to major bridges and tunnels [3]. In coordination with the Remote Sensing Laboratory at the Nevada Test Site, a neutron and gamma radiation detector was developed.

The INL digital cloud chamber is designed to determine what the radiation source is and from where it is coming. Equipping officers with dosimeters or specialized sport utility vehicles simply alert officers to the presence of radiation. Effective use of these detectors is very challenging in realistic urban environments due to high false alarm rates. In contrast, the cloud chamber could specifically alert an officer to whether the radiation is being emitted by plutonium and/or uranium, or a completely harmless source, such as a cancer patient or a truck full of bananas. This would result in a significantly lower false alarm rate.

In specifically adapting the cloud chamber design to a squad car, several design considerations were taken into account. The main concern is designing the chamber in such a way that it is small enough to not take up too much space in a police car already loaded with equipment, yet large enough to have adequately high detection sensitivity. In a purpose-built police car, INL envisions directly integrating the cloud chamber into the physical design of the car, such as installing the chambers within the car doors as shown in Figure 5. Although pressure vessels generally are manufactured in spherical or cylindrical shape, for a door, a pancake shape is more appropriate for a car door.

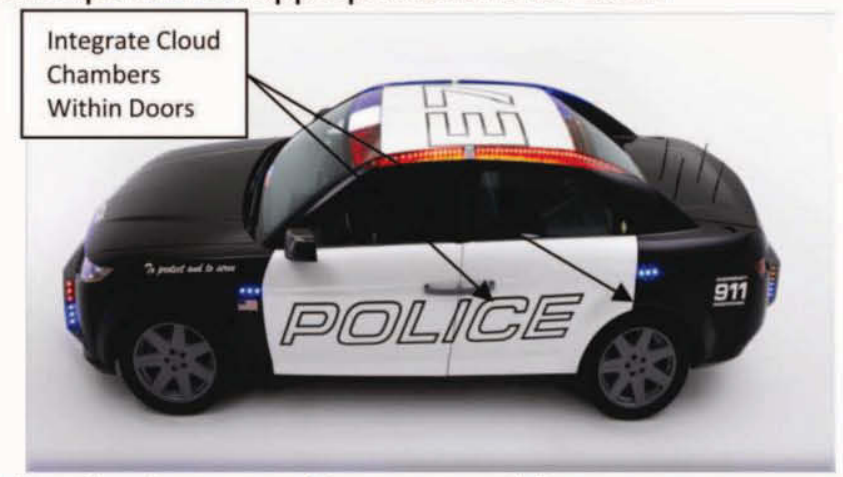

Figure 5: Conceptual cloud chamber integrated into automobile structure

\section{References}

1. Dasgupta, N.N. and S.K. Ghosh, A REPORT ON THE WILSON CLOUD CHAMBER AND ITS APPLICATIONS IN PHYSICS. Reviews of Modern Physics, 1946. 18(2): p. 225-290.

2. Yager, R.R. and L. Liu, Classic works of the Dempster-Shafer theory of belief functions. Studies in fuzziness and soft computing. 2008, Berlin; New York: Springer. xix, 806 p.

3. Lemire, J., NYPD cars get fitted with a Advanced Spectroscopic Portal Monitors (a.k.a radiation detectors, in New York Daily News. 2009: New York. 


\section{Using GPU Programming for Inverse Spectroscopy}

By Dr. David Gerts, Hugh Wimberly, Nathaniel Fredette Idaho National Laboratory

P.O. Box 1625, Idaho Falls, ID 83415

\section{Abstract:}

The Idaho National Laboratory (INL) has developed a detector that relies heavily on computationally expensive inverse spectroscopy algorithms to determine probabilistic three dimensional mappings of the source and intensity of a radioactive material. This inverse spectroscopy algorithm applies to material accountability by determining the location and strength of nuclear materials. Because of the computational expense, the INL has incorporated new hardware from the commercial graphics community. General programming for graphics processing units (GPUs) is not a new concept. However, the application of GPUs to evidence theory-based inverse spectroscopy is both novel and particularly apropos. Improvements while using a (slightly upgraded) standard PC are approximately three orders of magnitude, making a ninety-minute computation in less than six seconds. This significantly changes the concept of prohibitively expensive calculations and makes application to materials accountability possible in near real time, with the limiting condition reduced to sensor signal acquisition time.

\section{Introduction}

Inverse spectroscopy has application in a wide variety of nuclear materials and nuclear nonproliferation applications. The confirmation that a specific isotope is present in an unknown sample is an example of inverse spectroscopy. Furthermore, determining the intensity and location of an unknown radioactive sample is a more dramatic example of inverse spectroscopy. In order to address these types of known inverse spectroscopy applications in nuclear materials management, Idaho National Laboratory (INL) developed a novel algorithm to perform inverse spectroscopy.

INL's algorithm is based on using the electron energy, photon interaction site, and electron direction in the recreation of the 3D location and intensity of an unknown source. We expect, however, that all of the parameters based on the electron path will have significant uncertainties. A major question remains of how to use the information in the presence of significant uncertainty. Our answer is to use the Dempster-Shafer Theory of Evidence to combine the evidence of each electron path for a final data fusion solution.

\section{Review of Traditional Inverse Spectroscopy Methods}

A current area of interest in the field of nuclear nonproliferation concerns the ability to infer the identity and position of a radiation source through the analysis of a measured gamma spectrum output from a detection system. Historically, this spectrum analysis has been conducted through various peak-fitting techniques. These existing methods are sufficient to 
identify most radiation sources, but they both possess a significant shortcoming when applied to current detection problems. Peak fitting methods only generate functions that approximate the measured data and do not use any additional information about the source. Because of this, these methods cannot calculate the source position.

Various function approximation techniques have been employed to fit the measured output data of gamma detectors. An example is shown in Figure 1.

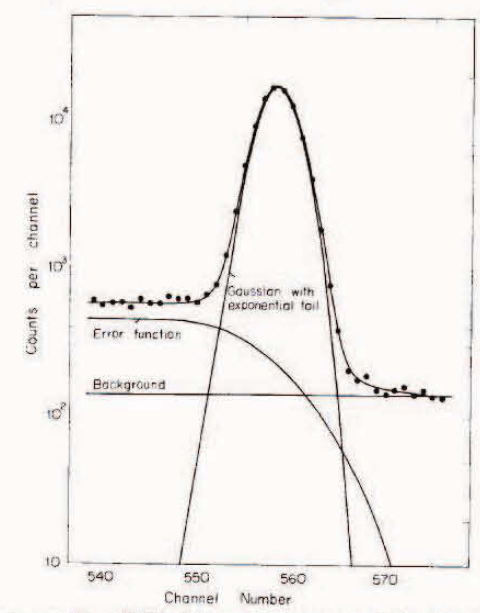

Figure 1: Example of fitting gamma spectrum with a function [1]

One of the simplest of these methods uses the principle of least squares to approximate the measured gamma spectra. In [2],Salmon uses a multichannel analyzer with $n$ channels numbered $1 \ldots i \ldots n$ to collect a gamma spectrum from a mixture of $m$ nuclides numbered $1 \ldots j \ldots$ $m$. Based on this system, a relationship between the count rate $a_{i j}$ in channel $i$ from nuclide $j$ and the count rate from mixture $b_{i}$ can be determined [1].

$$
b_{i}=\sum_{j=1}^{m} a_{i j} x_{j}+Z_{i},
$$

where $x_{j}$ is the ratio of the unknown activity to a corresponding standard activity and $Z_{i}$ is a random error. Finally, the method of least squares is applied where the random error $Z_{i}$ is minimized and a set of $m$ equations numbered $1 \ldots k \ldots m$ :

$$
\sum_{j=1}^{m} x_{j} \sum_{j=1}^{n} a_{i k} a_{i j}=\sum_{j=1}^{n} a_{i k} b_{i} .
$$

This system of equations then can be written in the form of $A x=y$ and can be solved by $x=A^{-1} y$.

In addition to the method of least squares, Gaussian-plus-exponential approximation has been used to recreate gamma spectra. In this approximation, the Gaussian and exponential tail shape was chosen because a typical gamma spectrum is expected to have a Gaussian count distribution around a photopeak energy with significantly more counts at energies lower than the photopeak energy due to scattering events. This method uses a linear approximation to model background radiation and is employed in the widely used gamma spectrum analysis tool SAMPO80 [3]. Because this Gaussian-plus-exponential approximation is only valid in the intervals of distinct photopeaks, search routines must be used to determine these intervals in the measured spectra. Once these intervals have been determined a normalized least squares fitting routine is used to generate shape calibration lines that determine the width and height of the Gaussian distribution and the junction points between the Gaussian, exponential and background functions. This method is summarized by Equations $\{3\}$ and $\{4\}$. 


$$
\chi^{2}=\sum_{i=k-l}^{k+m} \frac{\left(n_{i}-f_{i}\right)^{2}}{n_{i}},
$$

where $i$ is the channel number, $n_{i}$ is the number of counts in channel $i, k$ is the approximate center channel of the peak and $l$ and $m$ are the channels specifying the fitting interval. The function $f_{i}$ has the following values seen in Equation (4) based on the value of $i$

$$
\begin{aligned}
& f_{i}=p_{1}+p_{2}\left(i-p_{4}\right)+p_{3} e^{-\frac{1\left(i-p_{4}\right)^{2}}{2} p_{5}^{2}}, \text { for } p_{4}-p_{6}^{2} \leq i \leq p_{4}+p_{7}^{2} \\
& f_{i}=p_{1}+p_{2}\left(i-p_{4}\right)+p_{3} e^{-\frac{1}{2} p_{6}^{2} \frac{\left(2 i-2 p_{4}+p_{6}^{2}\right)}{p_{5}^{2}}}, \text { for } i<p_{4}+p_{7}^{2} \\
& f_{i}=p_{1}+p_{2}\left(i-p_{4}\right)+p_{3} e^{-\frac{1}{2} p_{7}^{2} \frac{\left(2 p_{4}-2 i+p_{7}^{2}\right)^{2}}{p_{5}^{2}}}, \text { for } i>p_{4}+p_{7}^{2},
\end{aligned}
$$

where $p_{1}$ is the constant in the continuum approximation, $p_{2}$ is the slope in the continuum approximation, $p_{3}$ is the height of the Gaussian, $p_{4}$ is the centroid of the Gaussian, $p_{5}$ is the width of the Gaussian, $p_{6}{ }^{2}$ is the distance in channels to the lower junction point between the background and exponential functions and $p_{7}^{2}$ is the distance in channels to the higher junction point between the Gaussian and exponential functions [4]. Finally, one more routine is used to determine the height of the Gaussian distributions and the coefficients of the polynomial approximation of the continuum. The routine uses a least squares technique:

$$
\chi^{2}=\sum_{i=k-l}^{k+m} \frac{\left(n_{i}-b_{i}-\sum_{j=1}^{n p} f_{i j}\right)^{2}}{n_{i}},
$$

where $i$ is the channel number, $n_{i}$ is the number of counts in channel $i, k$ is the reference channel for the background polynomial, $/$ and $m$ are the channels specifying the fitting interval, $\mathbf{b}_{\mathrm{i}}$ is the background function $b_{i}=p_{1}+p_{2}(i-k)+p_{3}(i-k)^{2}$, and $\mathrm{np}$ is the number of peaks in the interval [3]. The function $f_{i}$ in equation $\{5\}$ has the following values:

$$
\begin{aligned}
& f_{i j}=p_{2+2 j} e^{-\frac{1\left(i-p_{3+2 j}\right)^{2}}{w_{j}^{2}}}, \text { for } p_{3+2 j}-l_{j} \leq i \leq p_{3+2 j}+h_{j} \\
& f_{i j}=p_{2+2 j} e^{-\frac{1}{2} l_{j} \frac{\left(2 i-2 p_{3+2 j}+l_{j}\right)}{w_{j}^{2}}}, \text { for } i<p_{3+2 j}-l_{j} \\
& f_{i j}=p_{2+2 j} e^{-\frac{1}{2} h_{j} \frac{\left(2 p_{3+2 j}-2 i+h_{j}\right)}{w_{j}^{2}}}, \text { for } i>p_{3+2 j}+h_{j}
\end{aligned}
$$

where $p_{1}, p_{2}$, and $p_{3}$ define the continuum; $p_{2+2 j}$ and $p_{3+2 j}$ define the height and centroid of the $j^{\text {th }}$ peak; and $w_{j}, l_{j}$ and $h_{j}$ define the line shape by linearly interpolating the shape calibration results.

\section{Inverse Spectroscopy Using Electron Paths}

Compton scatter dominates the cross section in supersaturated air for energies of $100 \mathrm{keV}$ to $10 \mathrm{MeV}$, as shown in Figure 2. Because this encompasses nearly the entire gamma range for fission fragments, it is sufficient to incorporate only Compton scatter in a proof of principle algorithm for photons. Although the Compton relation and the associated Klein-Nishina formula are standard equations in neutral particle transport, they are rarely cast in a form that 
emphasizes the interacting electron. These equations are solved for the electron scatter angle and the electron energy. The electron energy and path are the observable quantities. The photon to electron scatter angle is the independent variable and the initial photon energy is calculable from these two parameters. The scattering geometry is shown in Figure 3 below.

Supersaturated Air

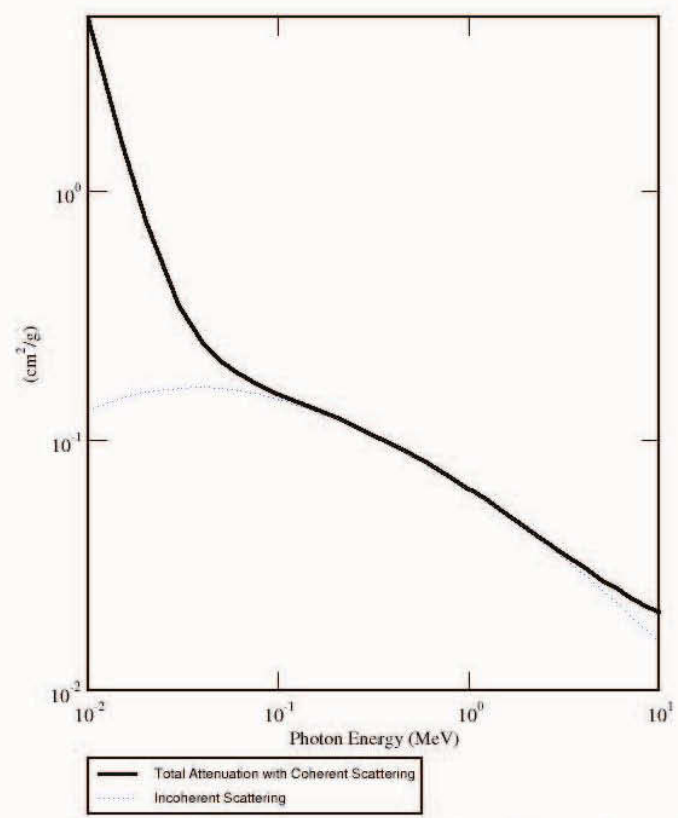

Figure 2: Photon cross section for supersaturated air ( 105\% humidity at 30oC) [5]

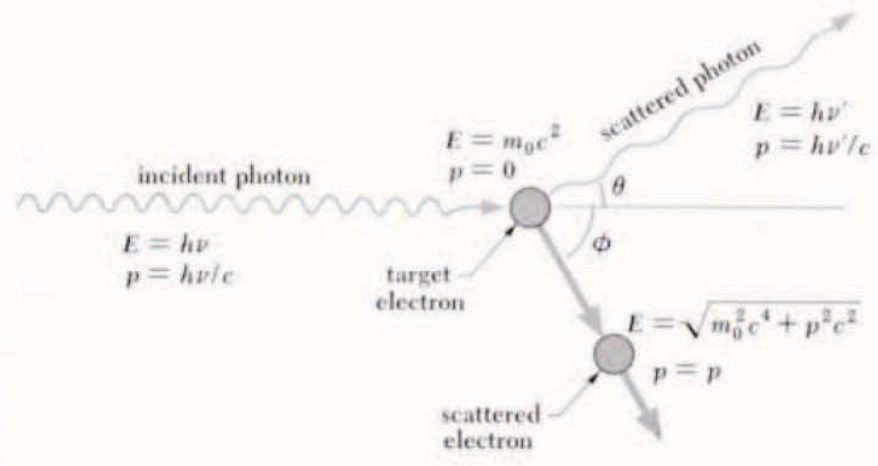

Figure 3: Compton scatter geometry [6]

The classic Compton relation for the energy of the electron, $E_{\text {elec }}$, given the scattering angle, $\varphi$, of the electron and the initial photon energy, $E_{o}$, is

$$
E_{\text {elec }}=E_{o} \frac{2^{E_{o}} / 511 \mathrm{keV} \operatorname{Cos}^{2}(\varphi)}{\left(1+E_{0} / 511 \mathrm{keV}\right)^{2}-\left(E_{o} / 511 \mathrm{keV}\right)^{2} \operatorname{Cos}^{2}(\varphi)} .
$$

The unpolarized, double differential in angle Klein-Nishina formula for the electron scatter angle based on the incident photon energy, scattered photon energy $E^{\prime}$, and the photon scatter angle, $\theta$, is 


$$
\frac{d \sigma_{\text {elec }}}{d \Omega}=\frac{r_{o}^{2}}{2}\left(\frac{E^{\prime}}{E_{o}}\right)^{2}\left(\frac{E_{o}}{E^{\prime}}+\frac{E^{\prime}}{E_{o}}-\operatorname{Sin}^{2}(\theta)\left(-\frac{4\left(1+{ }^{E_{o}} / 511 \mathrm{keV}\right)^{2} \operatorname{Cot}(\varphi) \operatorname{Csc}^{3}(\varphi)}{\left[\left(1+{ }^{E_{o}} / 511 \mathrm{keV}\right)^{2}+\operatorname{Cot}^{2}(\varphi)\right]^{2}}\right),\right.
$$

where $r_{o}$ is the classical electron radius. The first portion of the differential cross section is the familiar Klein-Nishina formula for photon scatter. The last parentheses, however, accounts for the electron scatter angle.

This formulation for the Klein-Nishina formula is not in a useable form for solving the inverse problem. Several more relations are needed. The relation between the photon scatter angle and the electron scatter angle is

$$
\theta=2 \operatorname{ArcTan}\left(\frac{\operatorname{Cot}(\varphi)}{1+{ }^{E_{o} / 511 \mathrm{keV}}}\right) .
$$

The relation between the incident photon energy, the scatter electron energy, and the scattered electron energy is

$$
E^{\prime}=E_{o}-E_{\text {elec }} .
$$

Equations $\{7\}$ through $\{10\}$ can be solved for the doubly differential cross section given the electron scatter energy in terms of the electron scatter angle, $\varphi$. The double differential cross section plotted in Figure 3 shows the electron scatter angle versus the interaction probability. The plot assumes that the electron energy was measured as $200 \mathrm{keV}$. In this case, the most probable angle between the electron and the incident photon was near zero degrees and has a maximum scatter angle of 66.136 degrees.

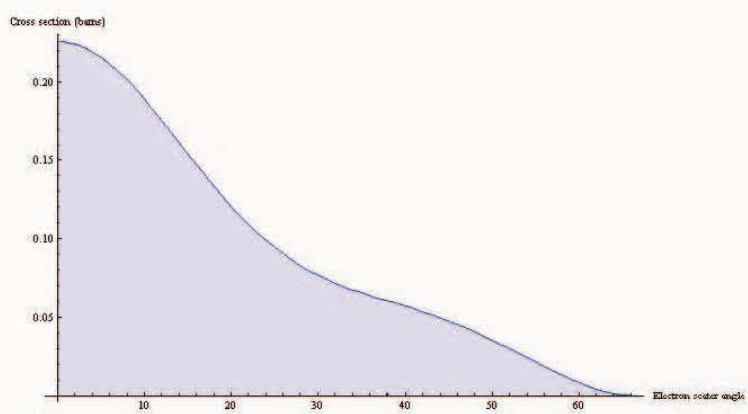

Figure 4: Double differential cross section for electron scatter angle given $200 \mathrm{keV}$ electron

The maximum scatter angle can be found by the equation

$$
\varphi_{\max }=\operatorname{ArcCos}\left(\frac{22.3607 E_{\text {elec }}}{\sqrt{511+500 E_{\text {elec }}}}\right),
$$

where $\varphi$ is in radians. Having a maximum scatter angle is simply the result of applying conservation of energy and momentum to the scattering problem.

The result of all of these calculations is a 3D mapping of probability of where the photon may have originally arisen. This can be shown as in Figure 5 where the green cloud represents probability of the original gamma source location. 

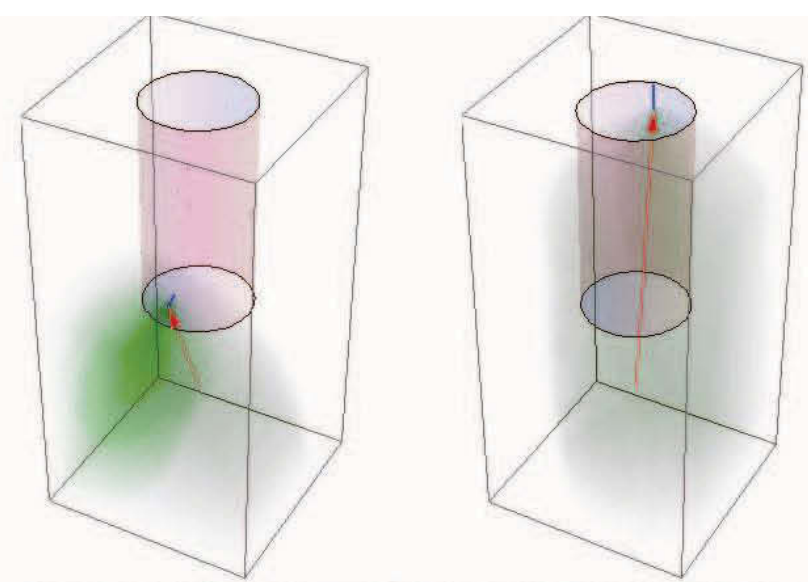

Figure 5: Probability maps for two sample electron tracks

This is clearly not the final solution because it has failed to account for background, scattered radiation from the source, and the uncertainty. In addition, the solution is clearly not unique. In fact, the focus of this research is not the calculation of the probability mappings, but rather, the addition of the probability mappings for many, many particle tracks.

\section{Dempster-Shafer Theory of Evidence}

Dempster-Shafer (DS) theory begins with a "question of interest." [7] It is important that this question be sufficiently broad. DS theory is based on the use of belief functions. In comparison, a probability function is additive, whereas a belief function is not, in general. The key to the concept of belief functions is the limited division of belief. Whereas probability functions assume that belief is apportioned to the points in the frame, belief functions allow basic probability numbers to be assigned to whole sets of points in the frame of discernment without further subdivision. The basic ideas is that a whole belief is divided into one or more basic probability numbers, $b(\mathrm{~A})$ and allocated to one or more subsets $\mathrm{A}$, called focal elements such that

$$
\sum\{b(A) \mid A \subseteq \Theta\}=1 .
$$

The basic probability number $b(A)$ allocated to a focal element $A$ is not further divided into smaller chunks allocated to proper subsets of $A$. These basic probability numbers are related to belief functions by

$$
\operatorname{Bel}(A)=\sum\{b(B) \mid B \subseteq A\},
$$

where $B$ represents proper subsets of $A$ and the summation is over all sets, $B$.

Given two pieces of evidence with basic probability numbers assigned to them, DS theory of belief functions combines the two (or more) pieces of evidence with the symbol, $\oplus$, using Dempster's orthogonal rule of combination [8],

$$
\begin{aligned}
& b=b_{1} \oplus b_{2} \\
& b\left(A_{i}\right)=\frac{\sum_{A_{p} \cap A_{q}=A_{i}} b_{1}\left(A_{p}\right) b_{2}\left(A_{q}\right)}{1-\sum_{A_{p} \cap A_{q}=\varnothing} b_{1}\left(A_{p}\right) b_{2}\left(A_{q}\right)} .
\end{aligned}
$$

Given these calculus mechanics, it is possible to combine any number of pieces of evidence in support of a particular answer within the frame of discernment (noting that answers can be combined into supersets within the frame of discernment). 
In short, using the Dempster-Shafer theory of evidence for sensor fusion reduces to a problem of determining basic probability numbers for the data to be evaluated, and then, interpreting the results. It is appropriate for an application that fundamentally relies on a random distribution of photons to arrive at a detector to specify the interaction density.

\section{Graphics Processing Unit Background}

Graphics processing units (GPUs) have traditinally been very limited, since they were designed for a very specific application. However, as the demands of computer gaming have skyrocketed, graphics cards have become increasingly capable. In recent years, due to the specialized nature of graphics processing, the raw throughput potential of GPUs has come to dramatically overshadow CPUs of a similar cost.

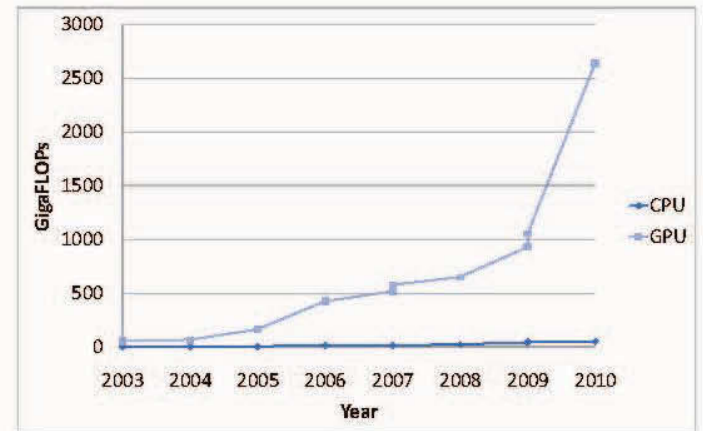

Figure 6: Computational power of cost-equivalent CPUs and GPUs

GPUs would already have replaced CPUs if not for the fact that GPUs are only designed to operate over a limited problem domain. Although they are incredibly fast, they are fundamentally designed to operate on pixels, colors, spatial vectors and positions. In this domain, integers are used more heavily than floating-point numbers, addition and multiplication are much more important than division or trancendental functions, and numerical precision is second to speed. Most importantly, GPUs are designed to operate on large numbers of independent data items, so they are heavily parallelized and heavily pipelined.

Due to increased interest in using the cheap-but-specialized GPUs for compute-intense projects and programs, NVIDIA and ATI have started increasing the capability of their graphic cards in non-traditional roles. The most significant hardware change has been to improve floating-point performance, especially for double-precision floating-point numbers, but the most significant overall change has been to make APIs and compilers available for programmers to use to more easily access the functionality of GPUs for general-purpose computing.

For our project, we used an NVIDIA GeForce GTX 285, a card that is no longer in production, but retailed for about $\$ 300$ at the time of our use. We used NVIDIA's Compute Unified Device Architecture (CUDA) [9], a set of extensions to $C$ that expose both low- and high-level operations on NVIDIA GPUs. Programming with CUDA primarialy requires an understanding of how CUDA parallelizes problems.

\section{GPU Rationale}

GPUs have many inherent characteristics that make them ideal for certain types of problems. Generally, for a problem to be a good fit for running on GPUs, it should satisfy the following principles.

1. Compute intensive: algorithms have a high arithmetic to input/output operation ratio. 
2. Low data interdependence: data elements can be operated upon without reading many other data elements.

3. Data locality: data elements dependent on each other are clustered closely in memory.

4. Small data types: data are well represented by 32-bit integers or single-precision floating-point numbers. Larger data types are available, but much more costly to use.

5. Basic operations: most operations are addition or multiplication rather than division or transcendental functions.

Problems that follow these principles should be able to be parallelized effectively and run efficiently on GPUs.

\section{CUDA Programming Concepts}
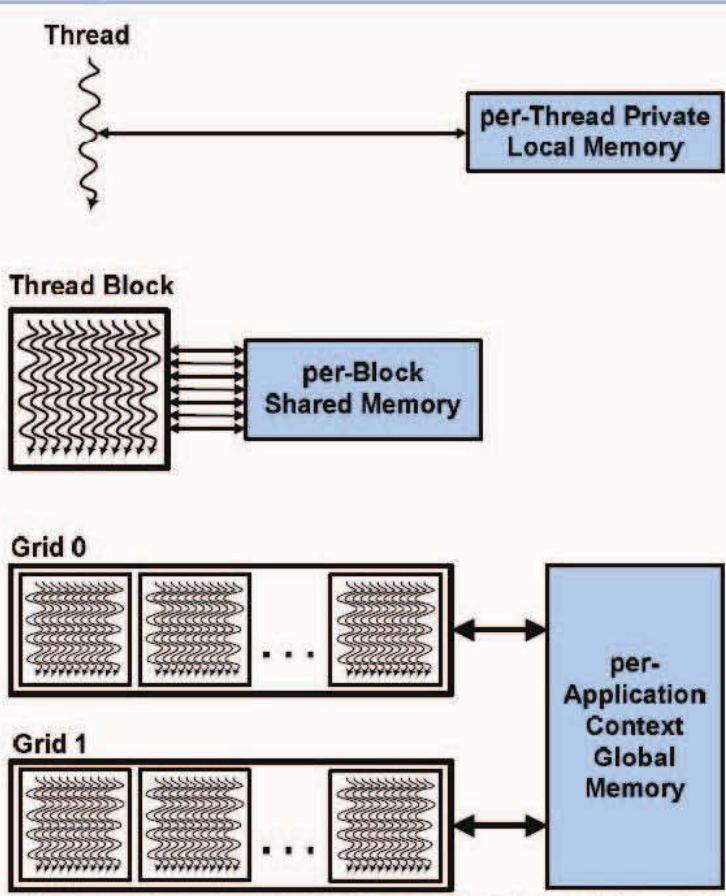

Figure 7: Diagram of CUDA Programming Architecture [9]

Code running on the CPU, called host code, calls a kernel function on blocks of data. Each kernel call is divided up into any number of blocks which can be exectuted in any order. Each block consists of up to 512 threads, grouped into warps no larger than 32 threads each. All the threads in a warp can potentially execute at the same time; as long as they perform the same operations, they remain in sync. As soon as one or more threads in a warp follows a branch that other threads do not, the different groups are serialized and one will be executed until completion before the remainder of the warp is executed. Thus, the ideal programming senario is one where conditional branches can be mostly or entirely avoided.

\section{Statement of the Problem}

Our approach is to use Dempster's Rule of Combination, given in equation $\{14\}$, on the probability maps from the electron tracks. Dempster's Rule of Combination, applied to each spatial cell, requires $\mathrm{O}\left(\mathrm{N}^{3}\right)$ operations. However, each of those operations requires foreknowledge of $\mathrm{K}$, the measure of conflict. $\mathrm{K}$ only needs to be calculated once for each group 
of combinations, but requires finding the summation of $\mathrm{O}\left(\mathrm{N}^{6}\right)$ products. In the case of $100 \times 100 \times 100$ cells, there are easily one trillion calculations (multiply and add operations, primarily). However, Dempster's rule of combination is trivial to parallel because the rows are independent of each other and can thus be calculated separately. Therefore, it makes for an ideal application on a graphics processing unit (GPU).

\section{Using GPUs for Dempster's Rule of Combination}

By far, the most expensive portion of combining two probability maps is computing the measure of conflict for the denominator. This could be represented in $\mathrm{C}++$ as the very simple nested loop:

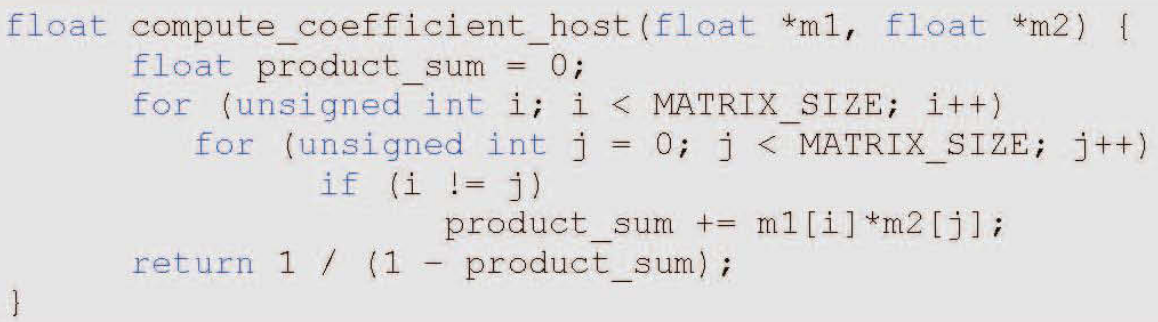

This computation is just an extensive multiply-accumulate, the kind of operation that is perfectly ideal for optimizing into FMAD (floating-point multiply-add) or FFMA (floating-point fused multiply-add) operations on a GPU. In CUDA, instead of calling the above computation, a CUDA kernel function would be called as below:

compute_coefficient_cuda $<<<$ NUM_BLOCKS, NUM_THREADS $>>>(m 1, \mathrm{~m} 2$, \&result) ;

To cause NUM_BLOCKS blocks, each with NUM_THREADS threads, to each compute the sum of a portion of the final coefficient. The GPU will start scheduling blocks in any order until it runs out of threads to allocate. On a modern GPU, this will generally result in 340-512 threads operating simultaneously. Since FMADs have a theoretical throughput of 8 per clock cycle per multiprocessor our theoretical speed for this function is $8 \mathrm{ops} / \mathrm{cycle} /$ multiprocessor $\times 30$ multiprocessors $\times 1476 \mathrm{MHz}$, or more than 350 GFLOPs.

\section{Results}

We found that altering the number of threads per block had a relatively small effect on total runtime. This makes sense; the GPU schedules blocks until it runs out of threads, so a higher threadcount per block leads to less overhead in certain problems but not necessarily more threads running at any given time. For all problem sizes, 256 threads worked well, with 128 threads performing very comparably.

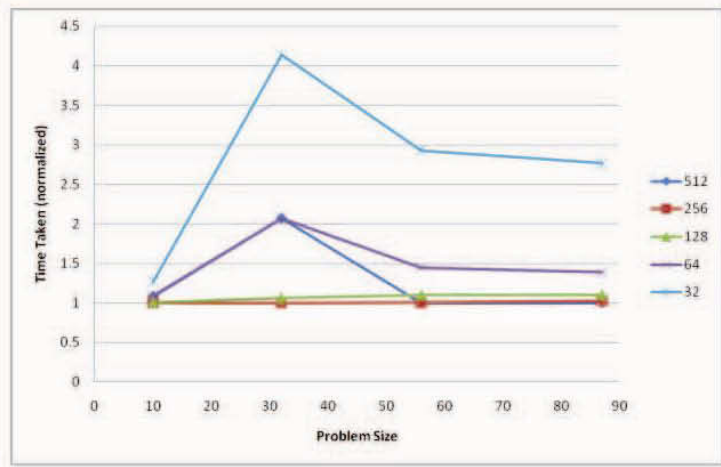

Figure 8: Normalized execution time for varying thread counts per block 
For the main kernel call, each thread summed 512 products required to compute the measure of conflict. After each such iteration, we put the numbers into an array which was summed and put into a "higher-order" array recursively, so that we required only $\mathrm{O}\left(\log _{512}\left(\mathrm{~N}^{6}\right)\right)$ additional memory. In addition to increasing computational efficiency, this striding helped preserve numerical stability.

The overhead for bussing data to and from the GPU on our machine was approximately $60 \mathrm{~ms}$; for $\mathrm{N}<40$, this time dominated the time required to get a solution. For our smallest test set, $\mathrm{N}=10$ and both the CPU and GPU computed the combination of two probability maps in less than a tenth of a second, with the GPU taking approximately four times as long. For all larger test sets, the time required by the CPU was much less than required by the GPU. We achieved our goal of three orders of magnitude speed-up for sufficiently large data sets.
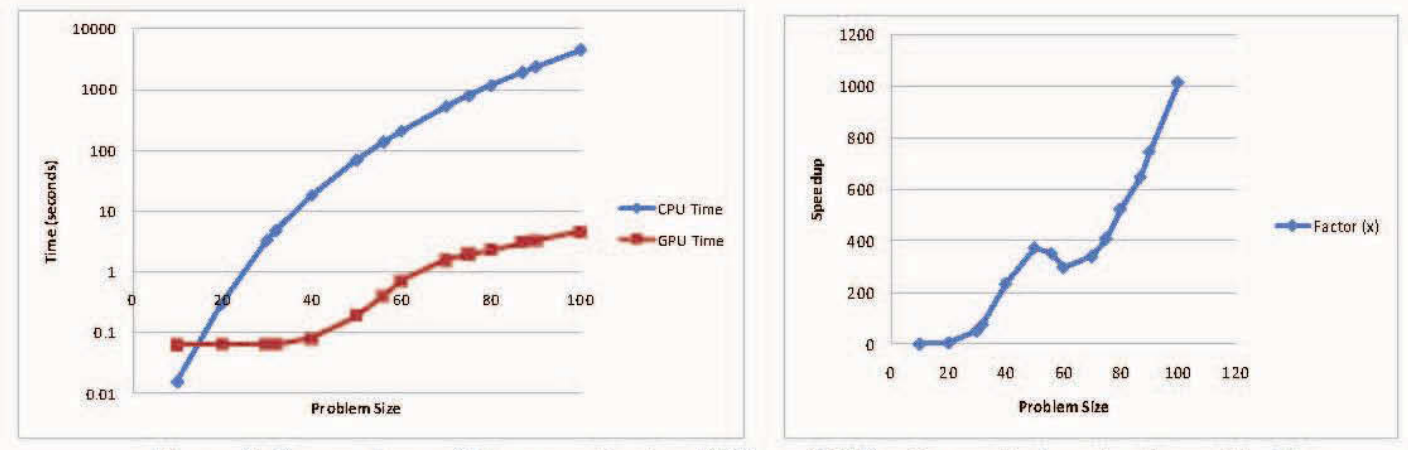

Figure 9: Comparison of time required on CPU vs. GPU for Dempster's rule of combination

\section{References}

1. Dojo, M., SHAPE FUNCTION OF PHOTOPEAKS FOR GAMMA-RAY SPECTRUM ANALYSIS WITH GE(LI) DETECTORS. Nuclear Instruments \& Methods, 1974. 115(2): p. 425-429.

2. Salmon, L., ANALYSIS OF GAMMA-RAY SCINTILLATION SPECTRA BYTHE METHOD OF LEAST SQUARES. Nuclear Instruments \& Methods, 1961. 14(2): p. 193-199.

3. Koskelo, M.J., P.A. Aarnio, and J.T. Routti, SAMPO80-MINICOMPUTER PROGRAM FOR GAMMA-SPECTRUM ANALYSIS WITH NUCLIDE IDENTIFICATION. Computer Physics Communications, 1981. 24(1): p. 11-35.

4. Routti, J.T. and S.G. Prussin, PHOTOPEAK METHOD FOR COMPUTER ANALYSIS OF GAMMA-RAY SPECTRA FROM SEMICONDUCTOR DETECTORS. Nuclear Instruments \& Methods, 1969. 72(2): p. 125-\&.

5. X-5_Monte_Carlo_Team, MCNP - A General Monte Carlo N-Particle Transport Code, Version 5. 2003.

6. Evans, R.D., The atomic nucleus. International series in pure and applied physics. 1955, New York,: McGraw-Hill. 972 p.

7. Yager, R.R. and L. Liu, Classic works of the Dempster-Shafer theory of belief functions. Studies in fuzziness and soft computing. 2008, Berlin ; New York: Springer. xix, 806 p.

8. Dempster, A.P., The Dempster-Shafer calculus for statisticians. International Journal of Approximate Reasoning, 2008. 48(2): p. 365-377.

9. NVIDIA's Next Generation CUDA Compute Architecture: Fermi. 2009; Available from: http://www.nvidia.com/content/PDF/fermi white papers/NVIDIA Fermi Compute Arc hitecture Whitepaper.pdf. 


\section{Appendix B}

\section{Analysis of Fuel and Salt Samples for Curium}

In order to assess the viability of using neutron signatures from $\mathrm{Cm}-244$ to track $\mathrm{Pu}$ through electrorefining and the rest of the pyroprocessing flowsheet, samples of spent fuel and salt were chemically analyzed in an attempt to detect Cm-244. Chemical analysis is critical to first establish that $\mathrm{Cm}-244$ can be detected and that its molar ratio to $\mathrm{Pu}$ is constant. If that can be established, then tracking $\mathrm{Cm}-244$ will be the equivalent of tracking $\mathrm{Pu}$.

The spent fuel samples were taken from several batches of chopped Experimental Breeder Reactor-II (EBR-II) blanket elements, also known as segments. The samples were measured via inductively coupled plasma mass spectroscopy (ICP-MS). A Cm standard containing $386 \mathrm{ng} / \mathrm{ml} \mathrm{of} \mathrm{Cm-244} \mathrm{was} \mathrm{used} \mathrm{for} \mathrm{this}$ analysis. It should be noted that $\mathrm{Cm}-244$ is the easiest $\mathrm{Cm}$ isotope to measure because of the absence of isobaric interferences and the long half-life (18.1 years). Table 1 shows the results of these analyses. All of the $\mathrm{Cm}$ isotopes were found to be below the detection limits for the analysis method.

Table 1. Chemical Analysis Results for Blanket Segments from Batches BCIB-081, -083, -085, -091, 093, -095, -098, -099, -101. *Batch 95 contained unirradiated fuel samples.

\begin{tabular}{|c|c|c|c|c|c|c|c|c|c|}
\hline Batch & Sample ID & 99-Tc & 139-La & Np-237 & 244-Cm & $245-\mathrm{Cm}$ & 246-Cm & 247-Cm & 248-Cm \\
\hline \multirow[t]{3}{*}{81} & SADZ394 & 63.2 & 89.9 & 45.4 & $<1.2$ & $<1.2$ & $<1.2$ & $<1.2$ & $<1.2$ \\
\hline & SADZ396 & 189 & 260 & 133 & $<1.2$ & $<1.2$ & $<1.2$ & $<1.2$ & $<1.2$ \\
\hline & SADZ398 & 71.9 & 101 & 51.3 & $<1.2$ & $<1.2$ & $<1.2$ & $<1.2$ & $<1.2$ \\
\hline \multirow[t]{3}{*}{83} & SADZ395 & 211 & 293 & 125 & $<1.3$ & $<1.3$ & $<1.3$ & $<1.3$ & $<1.3$ \\
\hline & SADZ416 & 987 & 1390 & 540 & $<1.3$ & $<1.3$ & $<1.3$ & $<1.3$ & $<1.3$ \\
\hline & SADZ450 & 210 & 291 & 124 & $<1.2$ & $<1.2$ & $<1.2$ & $<1.2$ & $<1.2$ \\
\hline \multirow[t]{2}{*}{85} & SADZ482 & 374 & 509 & 224 & $<1.7$ & $<1.7$ & $<1.7$ & $<1.7$ & $<1.7$ \\
\hline & SADZ484 & 330 & 454 & 191 & $<1.6$ & $<1.6$ & $<1.6$ & $<1.6$ & $<1.6$ \\
\hline \multirow[t]{3}{*}{91} & SADZ482 & 174 & 243 & 99.9 & $<1.3$ & $<1.3$ & $<1.3$ & $<1.3$ & $<1.3$ \\
\hline & SADZ471 & 874 & 1190 & 452 & $<1.3$ & $<1.3$ & $<1.3$ & $<1.3$ & $<1.3$ \\
\hline & SADZ484 & 294 & 409 & 169 & $<1.3$ & $<1.3$ & $<1.3$ & $<1.3$ & $<1.3$ \\
\hline \multirow[t]{3}{*}{93} & SADZ564 & 53.9 & 77.8 & 39.6 & $<1.3$ & $<1.3$ & $<1.3$ & $<1.3$ & $<1.3$ \\
\hline & SADZ572 & 93.7 & 131 & 67.7 & $<1.3$ & $<1.3$ & $<1.3$ & $<1.3$ & $<1.3$ \\
\hline & SADZ576 & 245 & 340 & 173 & $<1.3$ & $<1.3$ & $<1.3$ & $<1.3$ & $<1.3$ \\
\hline \multirow[t]{3}{*}{$95^{*}$} & SADZ571 & $<0.1$ & 2.02 & $<0.35$ & $<1.3$ & $<1.3$ & $<1.3$ & $<1.3$ & $<1.3$ \\
\hline & SADZ574 & $<0.1$ & 1.52 & $<0.34$ & $<1.3$ & $<1.3$ & $<1.3$ & $<1.3$ & $<1.3$ \\
\hline & SADZ577 & $<0.1$ & 1.65 & $<0.34$ & $<1.3$ & $<1.3$ & $<1.3$ & $<1.3$ & $<1.3$ \\
\hline \multirow[t]{3}{*}{98} & SADZ353A & 174 & 243 & 99.9 & $<1.3$ & $<1.3$ & $<1.3$ & $<1.3$ & $<1.3$ \\
\hline & SADZ359A & 874 & 1190 & 452 & $<1.3$ & $<1.3$ & $<1.3$ & $<1.3$ & $<1.3$ \\
\hline & SADZ361A & 294 & 409 & 169 & $<1.3$ & $<1.3$ & $<1.3$ & $<1.3$ & $<1.3$ \\
\hline \multirow[t]{3}{*}{99} & SADZ467 & 167 & 225 & 103 & $<1.3$ & $<1.3$ & $<1.3$ & $<1.3$ & $<1.3$ \\
\hline & SADZ485 & 750 & 1020 & 412 & $<1.3$ & $<1.3$ & $<1.3$ & $<1.3$ & $<1.3$ \\
\hline & SADZ513 & 102 & 143 & 65.2 & $<1.3$ & $<1.3$ & $<1.3$ & $<1.3$ & $<1.3$ \\
\hline \multirow[t]{3}{*}{101} & SADZ522B & 226 & 316 & 129 & $<1.3$ & $<1.3$ & $<1.3$ & $<1.3$ & $<1.3$ \\
\hline & SADZ524B & 1110 & 1520 & 531 & $<1.3$ & $<1.3$ & $<1.3$ & $<1.3$ & $<1.3$ \\
\hline & SADZ526B & 294 & 404 & 161 & $<1.3$ & $<1.3$ & $<1.3$ & $<1.3$ & $<1.3$ \\
\hline
\end{tabular}


The inability to measure $\mathrm{Cm}-244$ in any of the blanket segment samples was thought to be due to the relatively low amount of $\mathrm{Cm}$ in spent fast reactor (FR) fuel. Compared to spent light water reactor (LWR) fuel, FR fuel is known to be low in Cm content. While the vast majority of spent fuel electrorefined at INL is FR fuel from EBR-II, several small-scale experiments were run in the Hot Fuel Examination Facility (HFEF) at INL's Materials and Fuels Complex (MFC) using samples of spent fuel from the Belgian LWR, BR-3. The fuel was initially 8.3\% enriched in U-235. It was irradiated to a mean specific burn-up of $35.7 \mathrm{GWd} / \mathrm{t}$ and decayed for 26 years. Prior to electroreduction, it was crushed to particle sized of $<4 \mathrm{~mm}$, separated from cladding, sieved into discrete particle sizes ranging from 0.045 to $4 \mathrm{~mm}$, and extensively characterized for chemical and radiochemical constituent concentrations. A portion of the fuel fines $(<0.045 \mathrm{~mm})$ was sampled and analyzed. The results of this analysis are shown in Table 2. Cm-244 was detected, and its concentration quantified in BR-3 fuel samples analyzed at MFC. Based on this analysis, the mass ratio of $\mathrm{Pu}$ to $\mathrm{Cm}-244$ in the fuel was calculated to be $1.1 \times 10^{4}$.

Table 2. Chemical Analysis Results for Sample of Spent BR-3 Fuel.

\begin{tabular}{|c|c|c|c|}
\hline \multicolumn{2}{|c|}{ Major Components } & \multicolumn{2}{c|}{ Minor Components } \\
\hline Analyte & Wt\% & Analyte & Concentration \\
\hline $\mathrm{U}$ & 83.8 & Am-241 & $0.8 \mathrm{mCi} / \mathrm{g}$ \\
\hline $\mathrm{Pu}$ & 0.606 & $\mathrm{Cs}-137$ & $72 \mathrm{mCi} / \mathrm{g}$ \\
\hline $\mathrm{Ba}$ & 0.22 & $\mathrm{Am}-243$ & $10.5 \mathrm{ppm}$ \\
\hline $\mathrm{Ce}$ & 0.26 & $\mathrm{Ba}-137$ & $690 \mathrm{ppm}$ \\
\hline $\mathrm{La}$ & 0.13 & $\mathrm{Ba}-138$ & $1600 \mathrm{ppm}$ \\
\hline $\mathrm{Mo}$ & 0.26 & $\mathrm{Cm}-244$ & $0.55 \mathrm{ppm}$ \\
\hline $\mathrm{Nd}$ & 0.42 & $\mathrm{Cs}-133$ & $1420 \mathrm{ppm}$ \\
\hline $\mathrm{Pr}$ & 0.12 & $\mathrm{Cs}-135$ & $404 \mathrm{ppm}$ \\
\hline $\mathrm{Ru}$ & 0.12 & $\mathrm{Cs}-137$ & $753 \mathrm{ppm}$ \\
\hline $\mathrm{Zr}$ & 0.33 & $\mathrm{Rb}-87$ & $376 \mathrm{ppm}$ \\
\hline & & $\mathrm{Sr}-88$ & $444 \mathrm{ppm}$ \\
\hline & & $\mathrm{Sr}-90$ & $443 \mathrm{ppm}$ \\
\hline & & $\mathrm{Ag}$ & $45 \mathrm{ppm}$ \\
\hline & & $\mathrm{Cd}$ & $70 \mathrm{ppm}$ \\
\hline & & $\mathrm{Dy}$ & $10 \mathrm{ppm}$ \\
\hline & & $\mathrm{Eu}$ & $100 \mathrm{ppm}$ \\
\hline & & $\mathrm{Gd}$ & $60 \mathrm{ppm}$ \\
\hline & & $\mathrm{Pd}$ & $470 \mathrm{ppm}$ \\
\hline & & $\mathrm{Rb}$ & $530 \mathrm{ppm}$ \\
\hline & & $\mathrm{Rh}$ & $280 \mathrm{ppm}$ \\
\hline & & $\mathrm{Sm}$ & $830 \mathrm{ppm}$ \\
\hline & & $\mathrm{Sr}$ & $790 \mathrm{ppm}$ \\
\hline & & $\mathrm{Tc}$ & $540 \mathrm{ppm}$ \\
\hline & & $\mathrm{Te}$ & $490 \mathrm{ppm}$ \\
\hline & & & $560 \mathrm{ppm}$ \\
\hline
\end{tabular}

In one series of tests performed from 2005 to 2006, the BR-3 fuel was first reduced to metallic form and then electrorefined for the sake of achieving an integrated demonstration of pyroprocessing oxide fuel. These tests were run in a system known as the Hot Fuel Dissolution Apparatus (HFDA) that operates in the HFEF argon cell. A photograph of the HFDA is shown in Figure 1. The internal configuration for the HFDA that was used for electrorefining tests is shown in Figure 2 [ref. 1]. 
Figure 1. Photograph of the Hot Fuel Dissolution Apparatus (HFDA).

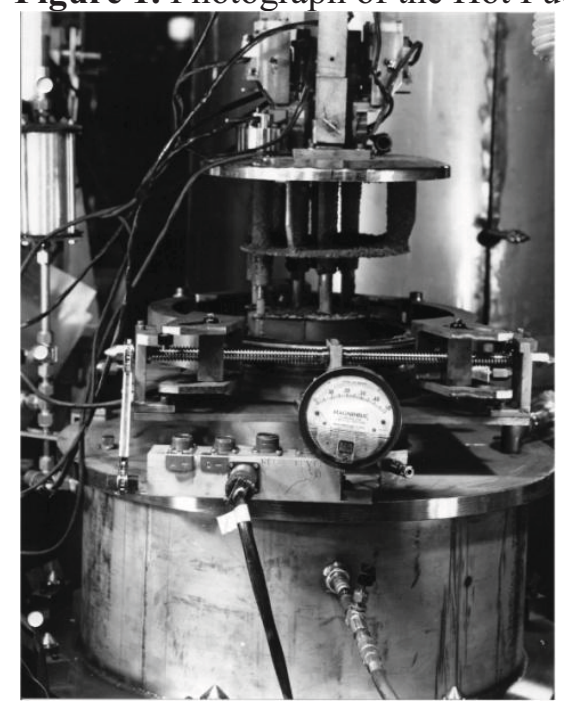

Figure 2. HFDA Configuration for BR-3 Fuel Electrorefining Tests.

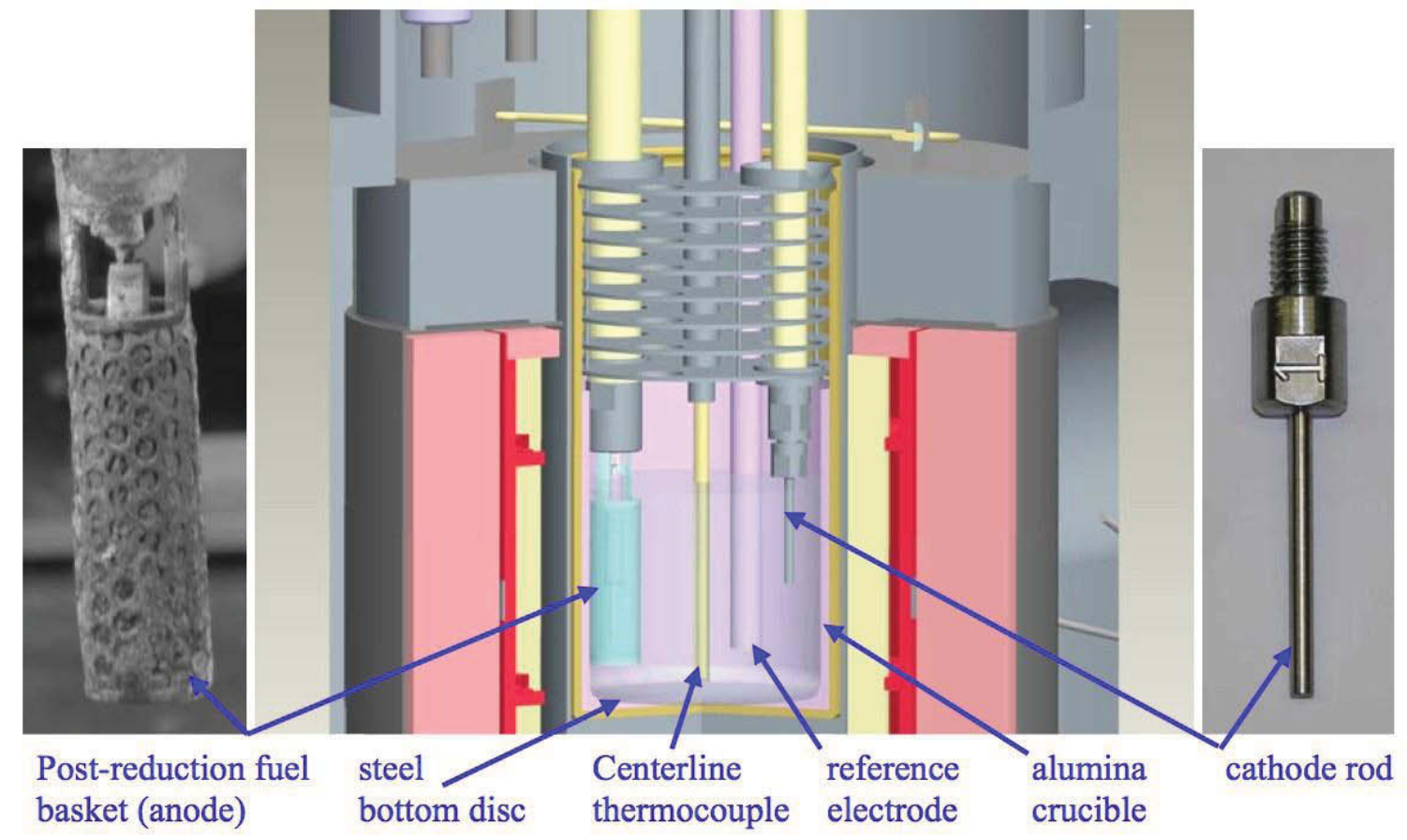

A total of 269.45 grams of $U$ was electrorefined in a single crucible (CRU-028) containing 790 grams of molten chloride salt. That salt is primarily composed of $\mathrm{LiCl}-\mathrm{KCl}$ in a eutectic composition but also included up to $9 \mathrm{wt} \%$ uranium in the form of $\mathrm{UCl}_{3}$. Elements in the spent fuel that are chemically more active than $\mathrm{U}$ will interact with $\mathrm{UCl}_{3}$ and partition into the salt. Minor actinides such as $\mathrm{Pu}$ and $\mathrm{Cm}$ are included in the group of elements that are chemically more active than $U$ and will partition into the salt phase. CRU-028 with most of its initial salt charge has been stored in the HFEF argon cell since the completion of the electrorefining tests. It was, thus, decided to sample this salt and analyze for $\mathrm{Pu}$ and $\mathrm{Cm}-244$.

Assuming all of the $\mathrm{Pu}$ and $\mathrm{Cm}-244$ from the spent fuel end up in the salt phase, it is estimated that their concentrations in the salt should have been 2040 and 0.19 ppm, respectively. As shown in Table 3, 
the measured concentrations were significantly less. Total Pu (assuming only Pu-239 and Pu-240) was only 1060 to $1080 \mathrm{ppm}$, a factor of 1.9 less than anticipated. And Cm-244 was below the detection limit, which had been estimated to be $0.2 \mathrm{ppm}$. If the $\mathrm{Pu} / \mathrm{Cm}-244$ ratio had in fact remained constant through the various steps of the process, then the $\mathrm{Cm}-244$ concentration would be about $0.1 \mathrm{ppm}$. This would be consistent with none being detected, as the detection limit is specified as $0.2 \mathrm{ppm}$. It is not clear what the source is for the discrepancy between fuel composition and salt composition. It is possible that not all of the minor actinides partitioned into the salt phase due to incomplete reduction of the oxide or incomplete chlorination of the reduced metal. $\mathrm{But} \mathrm{PuO}_{2}$ reduction levels were typically $98 \%$ or greater, and the other minor actinides are expected to behave similarly. Other possible explanations include non-representative results for the analysis of the BR-3 fuel, oxidative precipitation of actinide chlorides from the salt, and phase segregation on cooling of the salt. Regardless of the explanation, however, these results reveal the extreme difficulty involved with quantifying Cm-244 concentrations well enough to eventually validate a Pu-tracking method based on neutron-based measurements that rely on a steady ratio of $\mathrm{Cm}$ to $\mathrm{Pu}$ in the system.

Table 3. Chemical Analysis Results for Salt Samples taken from Crucible CRU-028 Reference INL Materials and Fuels Complex Analytical Laboratory Log \# 92355, 92356, and 92357.

\begin{tabular}{|c|c|c|c|}
\hline \multirow[t]{2}{*}{ Analyte } & SADM22 & SADM23 & SADM24 \\
\hline & \multicolumn{3}{|c|}{ Concentration (ppm) } \\
\hline $\mathrm{U}-235$ & 817 & 789 & 797 \\
\hline U-238 & 18030 & 17630 & 17740 \\
\hline Pu-239 & 876 & 867 & 889 \\
\hline $\mathrm{Pu}-240$ & 199 & 190 & 193 \\
\hline $241 \mathrm{M} / \mathrm{Z}$ & 110 & 110 & 112 \\
\hline $243 \mathrm{M} / \mathrm{Z}$ & 2.14 & 1.58 & 1.54 \\
\hline $\mathrm{Cm}-244$ & $<0.2$ & $<0.2$ & $<0.2$ \\
\hline $\mathrm{Cm}-245$ & $<0.2$ & $<0.2$ & $<0.2$ \\
\hline $\mathrm{Cm}-246$ & $<0.2$ & $<0.2$ & $<0.2$ \\
\hline $\mathrm{Cm}-247$ & $<0.2$ & $<0.2$ & $<0.2$ \\
\hline $\mathrm{Cm}-248$ & $<0.2$ & $<0.2$ & $<0.2$ \\
\hline
\end{tabular}

Note that the $243 \mathrm{M} / \mathrm{Z}$ concentrations given in Table 3 could be from either Am-243 or Cm-243, but there is currently no practical analytical method for separating Am from Cm. Also, the relatively high concentrations of this species (1.5 to $2.1 \mathrm{ppm}$ ) are highly suggestive that it is, in fact, Am-243.

\section{Path Forward/Recommendation}

The results of these salt and fuel analyses do not refute the concept of using $\mathrm{Cm}-244$ concentration to track Pu through the electrorefining process. However, they do demonstrate the difficulty involved with validating this approach. Not only is it necessary to have samples from processing spent LWR fuel. But there must also be a significant accumulation from processing multiple batches of this fuel in order to have enough $\mathrm{Cm}-244$ to detect via chemical analysis. Given that large scale pyroprocessing activities at INL are currently limited to spent metal fuel, there is no quick or cheap path to obtaining samples affected by processing large quantities of oxide spent fuel.

Alternatives for further examining this method for tracking $\mathrm{Pu}$ in the process are not plentiful. New method development by the MFC Analytical Laboratory could be initiated to examine options for increasing analytical sensitivity, such as pre-concentrating the samples and switching to using the thermal ionization mass spectrometer (TIMS) rather than the ICP-MS. However, the AL currently does not have a suitable spike material. Between the cost of obtaining such a spike material and the time involved with 
method development, pursuing this route would be expensive and still not guarantee a satisfactory outcome.

\section{References:}

1. S. D. Herrmann and S. X. Li, "Separation and Recovery of Uranium Metal from Spent Light Water Reactor Fuel via Electrolytic Reduction and Electrorefining," Nuclear Technology, 171 (3), 247, September 2010. 


\section{Appendix C}

\section{Technical Evaluation for Safeguards Equipment Installation}




\section{Technical Evaluation Study}

\section{IAEA Equipment Installation}

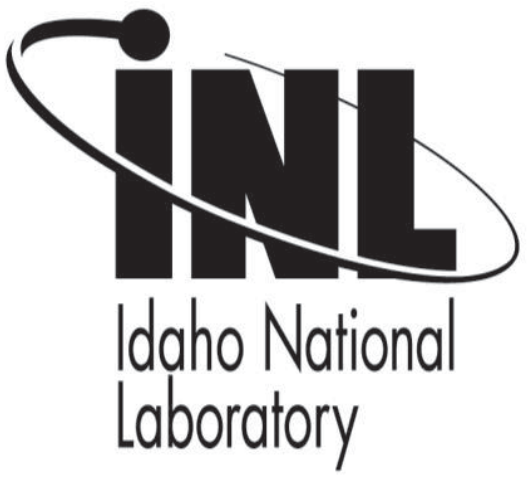

The INL is a U.S. Department of Energy National Laboratory operated by Battelle Energy Alliance. 
Idaho National Laboratory

IAEA EQUIPMENT INSTALLATION

Materials and Fuels Complex

Manual: Stand Alone

Software System Design

Description

USE TYPE N/A eCR Number: 581488

\section{REVISION LOG}

\begin{tabular}{|c|c|c|c|}
\hline Rev. & Date & Affected Pages & Revision Description \\
\hline 0 & $? / ? / ?$ & All & New issue. See eCR 581488 \\
\hline & & & \\
\hline & & & \\
\hline & & & \\
\hline & & & \\
\hline & & & \\
\hline & & & \\
\hline & & & \\
\hline & & & \\
\hline & & & \\
\hline
\end{tabular}




\begin{tabular}{|l|lll|} 
IAEA EQUIPMENT INSTALLATION & $\begin{array}{l}\text { Identifier: } \\
\text { Revision: }\end{array}$ & 0 & \\
Effective Date: & $08 / 31 / 2010$ & Page: 2 of $\mathbf{3 4}$ \\
\hline
\end{tabular}

\section{CONTENTS}

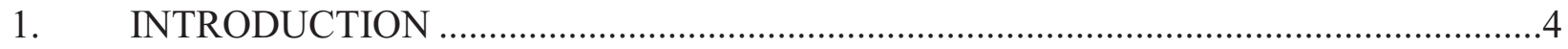

1.1 Description of the Proposed Issue or System ................................................

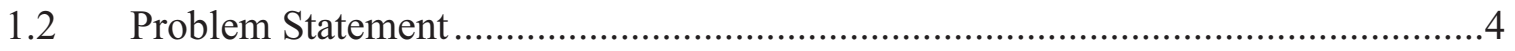

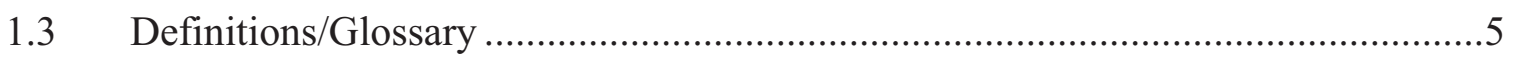

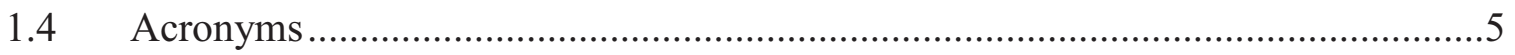

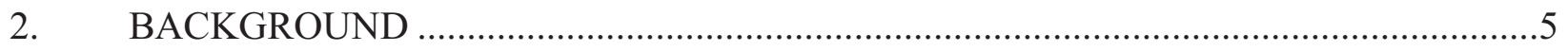

2.1 Facility, Structure, System, Component Functions .......................................

2.2 Facility, Structure, System, Component Classification ....................................

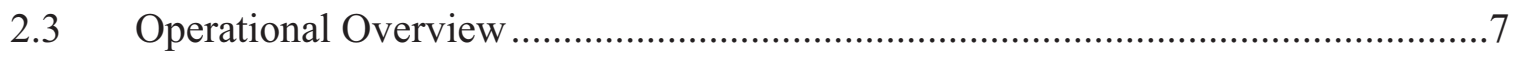

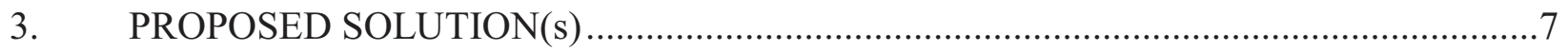

3.1 Elements/Functions of Proposed Solution(s) .............................................19

3.2 Detailed Evaluation - Alternative \#1: North Wall Feedthrough and Data Collection Station/Table 9A NW Camera Mount.

3.3 Detailed Evaluation - Alternative \#2: North Wall Feedthrough and Data Collection Station/Table 9A SW Camera Mount

3.4 Detailed Evaluation - Alternative \#3: South Wall Feedthrough and Data Collection Station/Angle Bracket Camera Mount

3.5 Detailed Evaluation - Alternative \#4: North Wall Feedthrough and Data Collection Station/Window 8A Bracket Camera Mount

3.6 Detailed Evaluation - Alternative \#5: South Wall Feedthrough and Data Collection Station/Manipulator Feedthrough Camera Mount

3.7 Detailed Evaluation - Alternative \#6: South Wall Feedthrough and Data Collection Station/Periscope Camera Mount

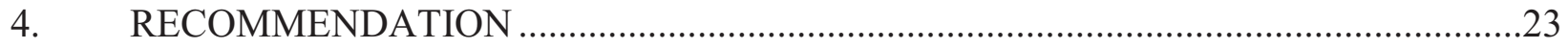

5. IMPLEMENTATION, SCHEDULE \& COST ...........................................................24

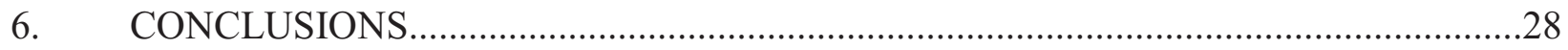


IAEA EQUIPMENT INSTALLATION Identifier: TEV-916 Revision: $\quad 0$

7. APPENDIXES . .28

Appendix A Vendor Datasheets/INL Drawings for Pre-Conceptual Equipment . 


\begin{tabular}{|l|lll|}
\hline IAEA EQUIPMENT INSTALLATION & Identifier: & TEV-916 & \\
& Revision: & 0 & \\
Effective Date: & $08 / 31 / 2010$ & Page: 4 of $\mathbf{3 4}$ \\
\hline
\end{tabular}

\section{INTRODUCTION}

National and Homeland Security has determined that it is necessary to demonstrate the use of camera technology within a hot cell environment to detect and deter proliferation of special nuclear materials.

\section{- Goals}

The overall goal of the project is to monitor an access port (Small Transfer Lock) in the Fuel Cycle Facility (FCF) air cell. The camera system shall consist of one or two cameras, shall provide pan/tilt/zoom capabilities, shall have vertical adjustment (if required) to facilitate vision when objects are placed in front of the unit, and shall provide a redundant camera system for verification. A local data collection station shall be positioned outside of the air cell to record the visual input. Any air cell modifications that are necessary to support the equipment shall be identified and considered.

\section{- Objectives}

The objectives of this Technical Evaluation are to: determine the appropriate method for placing a camera system within the FCF air cell; evaluate potential locations for mounting the camera system; identify potential feedthrough locations; determine the preferred location for a data collection system; provide engineering costs and schedule; provide general equipment recommendations.

\section{- Deliverables}

The required deliverables for this Technical Evaluation are to: identify the preferred location for the in cell cameras; identify the feedthroughs for the preferred camera location; identify the physical location for the data collection system given the in-cell preferred camera location, identify potential camera equipment selection criteria, identify potential camera mounting equipment, and identify the processes and engineering cost to achieve the identified alternatives.

\subsection{Description of the Proposed Issue or System}

The envisioned system for surveillance and documentation of the FCF air cell access port will require two zoom cameras on pan/tilt mounts, a mount to tie the camera system to the air cell equipment or boundary, a data collection system located outside of the air cell confinement boundary, and cabling to transmit power and signals between the camera system and data acquisition system.

\subsection{Problem Statement}

The air cell at FCF is congested and this Technical Evaluation is required to ensure a camera system will have optimum visibility, will not intrude in normal 
IAEA EQUIPMENT INSTALLATION $\begin{array}{ll}\text { Identifier: } & \text { TEV-916 } \\ \text { Revision: } & 0 \\ \text { Effective Date: } & 08 / 31 / 2010\end{array}$
Page: 5 of 34

cell operations, and is in a location that will prevent accidental damage. In addition, there is limited space for a data collection system on the north side of the cell - the physical limitations for operator workstations must be considered. Finally, the electrical and feedthrough requirements to support a camera system must be evaluated to determine if camera locations can be supported with conveniently located penetrations. Cable management within the cell is of primary concern, and the location of the feedthroughs must be optimized to facilitate ease of cable management - cables must not interfere with normal cell operations.

\subsection{Definitions/Glossary}

None.

\subsection{Acronyms}

EMM - Electromechanical Manipulator

FCF - Fuel Cycle Facility

INL - Idaho National Laboratory

SAR - Safety Analysis Report

\section{BACKGROUND}

Cameras have been used within hot cell environments at the Idaho National Laboratory (INL), and other Department of Energy facilities, for a number of years to aid operators in viewing non-line-of-sight objects, and to provide magnification of objects within the normal working envelope. The Idaho National Laboratory has extensive experience with using both commercial and special radiation hardened equipment in hot cell applications. While this equipment has been used for assisting operators in performing fundamental tasks within the cell, cameras have not been employed for surveillance activities related to special nuclear material proliferation deterrence. This project is a proof-of-principle endeavor to document the viability of utilizing in-cell camera monitoring equipment for the purpose of safeguarding nuclear materials.

The camera and data acquisition systems shall provide the capabilities required to perform the following:

- Provide pan/tilt/zoom motion to facilitate monitoring of the Small Transfer Lock

- Potentially provide the capability to adjust the vertical placement of cameras to accommodate items placed between the camera(s) and the Small Transfer 
IAEA EQUIPMENT INSTALLATION
Identifier: Revision: $\quad 0$

Effective Date: $08 / 31 / 2010$

TEV-916

0
Page: 6 of 34

Lock. Vertical adjustment could be provided to the vertical ballscrew unit via a manipulator.

- The system shall function in accordance with the facility Safety Analysis Report (SAR) and the System Design Description.

- The system shall be fabricated according to the quality level determination for the project.

The FCF air cell is the proposed location for testing of a special nuclear materials proliferation monitoring system. The following INL drawings were consulted for background on the FCF air cell:

704572 - FCF Air Cell

704587 - FCF Air Cell (Future)

740204 - FCF Air Cell Penetrations

704601 - EMM Characteristics

705305 - EMM Tee Handle

698826 - FCF E/M Handle to Crane Hook Adaptor (In Cell)

715417 - Electrical Feedthru Fabriction Layout (Air Cell Wall)

740037 - Air Cell Manipulator Penetration Liner Assembly

759116 - Master-Slave Manipulator System 50 Illustration of Lead Shielding

759117 - Master-Slave Manipulator Mod. J Thru Tube \& Transfer Box Assembly

718060 - HFEF Pens. 12.1001 Thru 12.1026, 12.2001, 12.2002, Periscope Penetrations

The facility SAR (F0000-0018-AK, Fuel Conditioning Facility Final Safety Analysis Report) provides the structural and safety requirements for the air cell boundary and internal equipment.

The system design description for the argon and air cells (SDD-252, FCF Argon Cell Confinement Boundary \& Argon and Air Cell Shielding Systems) provides an overview on the penetrations for the air cell.

The overall system cost, including engineering effort, equipment, fabrication, documentation, and installation, shall be minimized as much as practical. 


\begin{tabular}{|l|lll|}
\hline IAEA EQUIPMENT INSTALLATION & Identifier: & TEV-916 \\
Revision: & 0 & \\
& Effective Date: & $08 / 31 / 2010$ & Page: 7 of 34 \\
\hline
\end{tabular}

\subsection{Facility, Structure, System, Component Functions}

FCF Air Cell boundary feedthroughs

\subsection{Facility, Structure, System, Component Classification}

FCF Air Cell confinement boundary system (including feedthroughs) is classified as Safety-Significant, per SDD-252 section 2.2.

\subsection{Operational Overview}

See section 2.3 of SDD-252 "FCF Argon Cell Confinement Boundary \& Argon and Air Cell Shielding Systems" for an operational overview of the FCF air cell.

\section{PROPOSED SOLUTION(s)}

Following are six discrete camera alternatives for viewing the Small Transfer Lock. See Sketch 1 for a plan view of proposed camera system locations. Space requirements are based on a standard 19" rack footprint of 29"W X 30"D and evaluation of operator accessibility to work at the window. 


\section{IAEA EQUIPMENT INSTALLATION} Identifier:

TEV-916 Revision: 0 Effective Date: $08 / 31 / 2010$

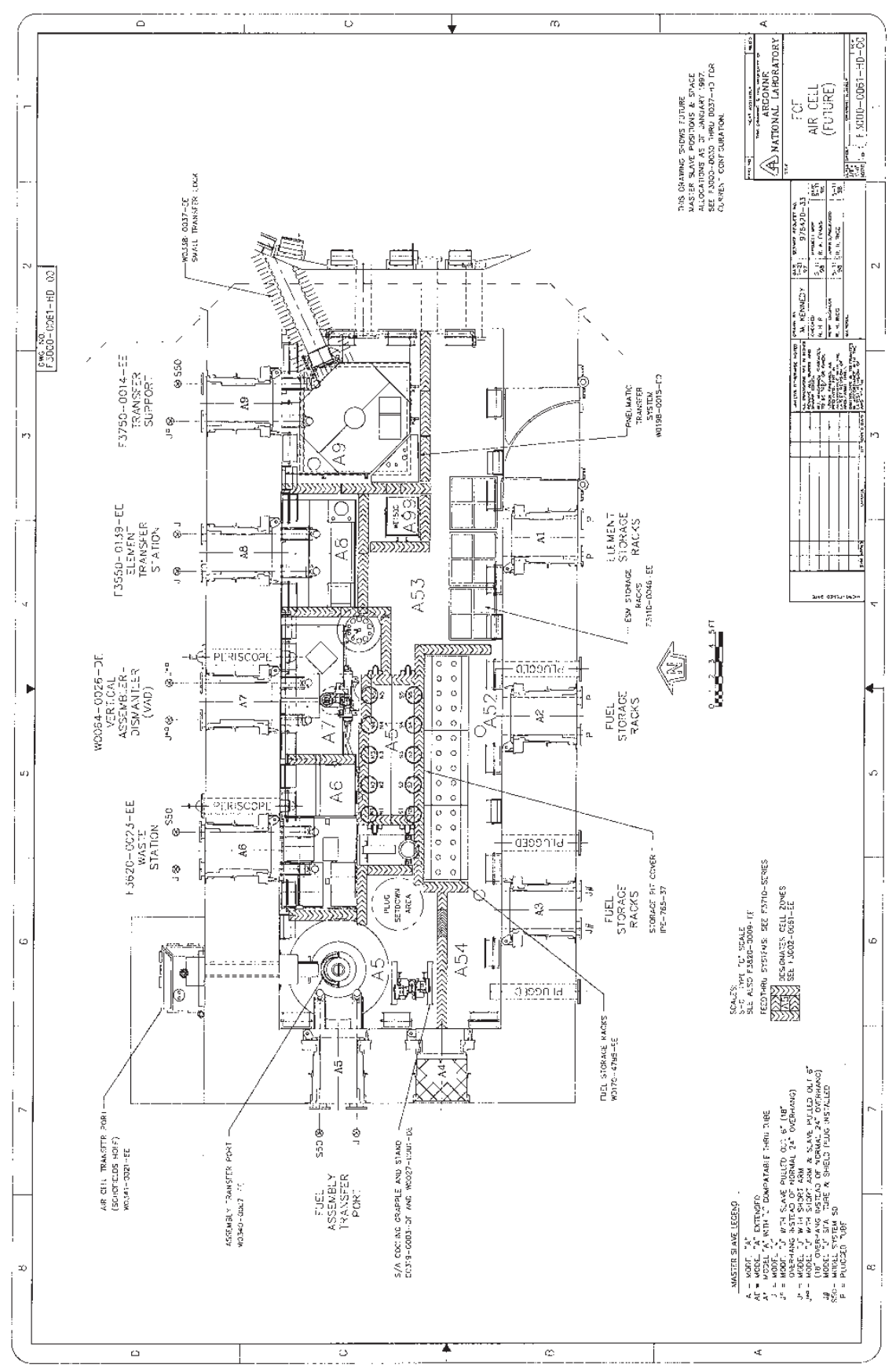

Sketch 1. Plan view of proposed camera system locations. 


\begin{tabular}{|c|lll|}
\hline \multirow{2}{*}{ IAEA EQUIPMENT INSTALLATION } & Identifier: & TEV-916 & \\
& Revision: & 0 & \\
& Effective Date: & $08 / 31 / 2010$ & Page: 9 of $\mathbf{3 4}$ \\
\hline
\end{tabular}

Alternative \#1 - North Wall Feedthrough and Data Collection Station/Table 9A NW Camera Mount

Adjacent to the Small Transfer Lock, located at the interface between the air and Argonne cells, is table A-9 (see picture 1 below). The northwest corner of the table remains stationary during all operations and is a possible location for camera mounting. The camera mounting system would be composed of a vertical ballscrew drive with an attached table, connected to twin rails (See Appendix A). The camera mounting unit would hang from the side of the table and would be held stationary through a series of clamps that are set using the master-slave manipulators at Window 9A. The cameras used for this application would be radiation hardened and would utilize pan/tilt/zoom capabilities (See Appendix A).

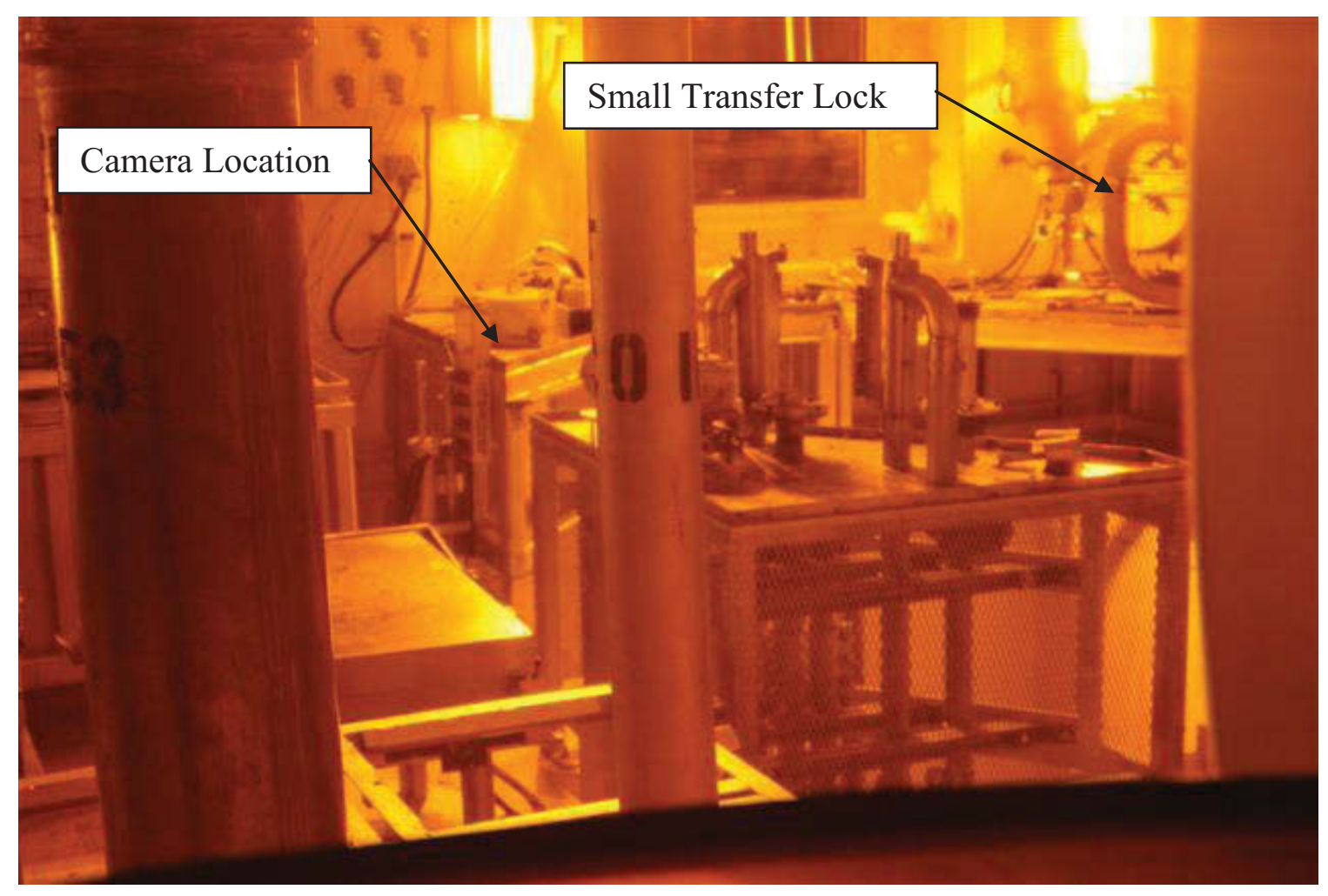

\section{Picture 1. Camera location for Alternative \#1 (viewed from south wall).}

Feedthroughs 9.01 through 9.06 at Window 9A are potential candidates to provide power and signal to the camera unit. Vertical adjustment would be provided to the vertical ballscrew unit via a manipulator. A data collection system (See Appendix A) would be located adjacent to Window 9A (See Picture 2 below). 


\begin{tabular}{|c|c|c|c|}
\hline IAEA EQUIPMENT INSTALLATION & $\begin{array}{l}\text { Identifier: } \\
\text { Revision: } \\
\text { Effective Date: }\end{array}$ & $\begin{array}{l}\text { TEV-916 } \\
0 \\
08 / 31 / 2010\end{array}$ & Page: 10 of $\mathbf{3 4}$ \\
\hline
\end{tabular}

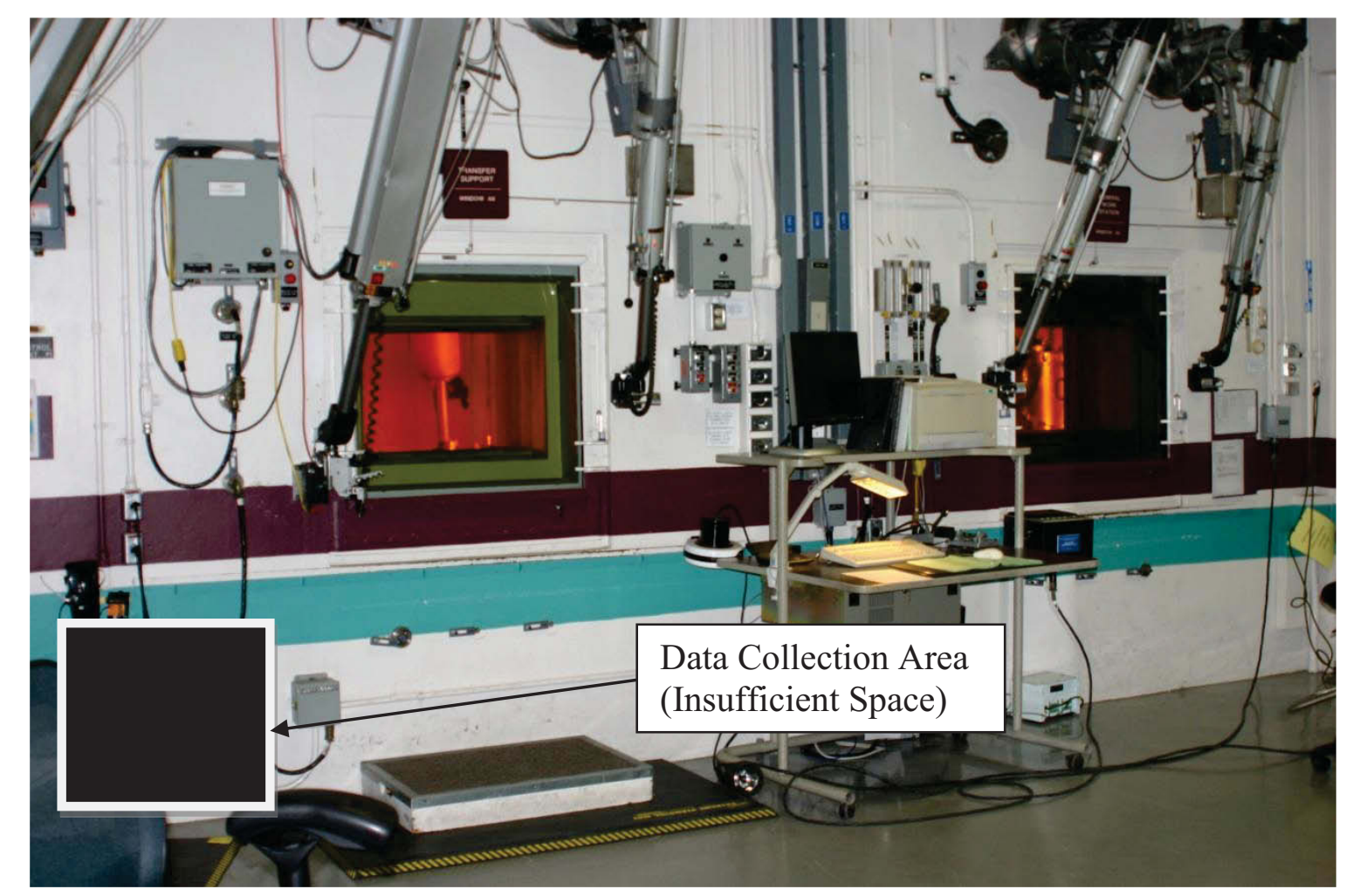

\section{Picture 2. Data Collection System location for Alternative \#1.}

Alternative \#2 - North Wall Feedthrough and Data Collection Station/Table 9A SW

\section{Camera Mount}

This alternative is identical to alternative \#1 with the exception of the camera mounting location. Location \#2 is on the Northwest corner of Table 9A (See Picture 3 below). 


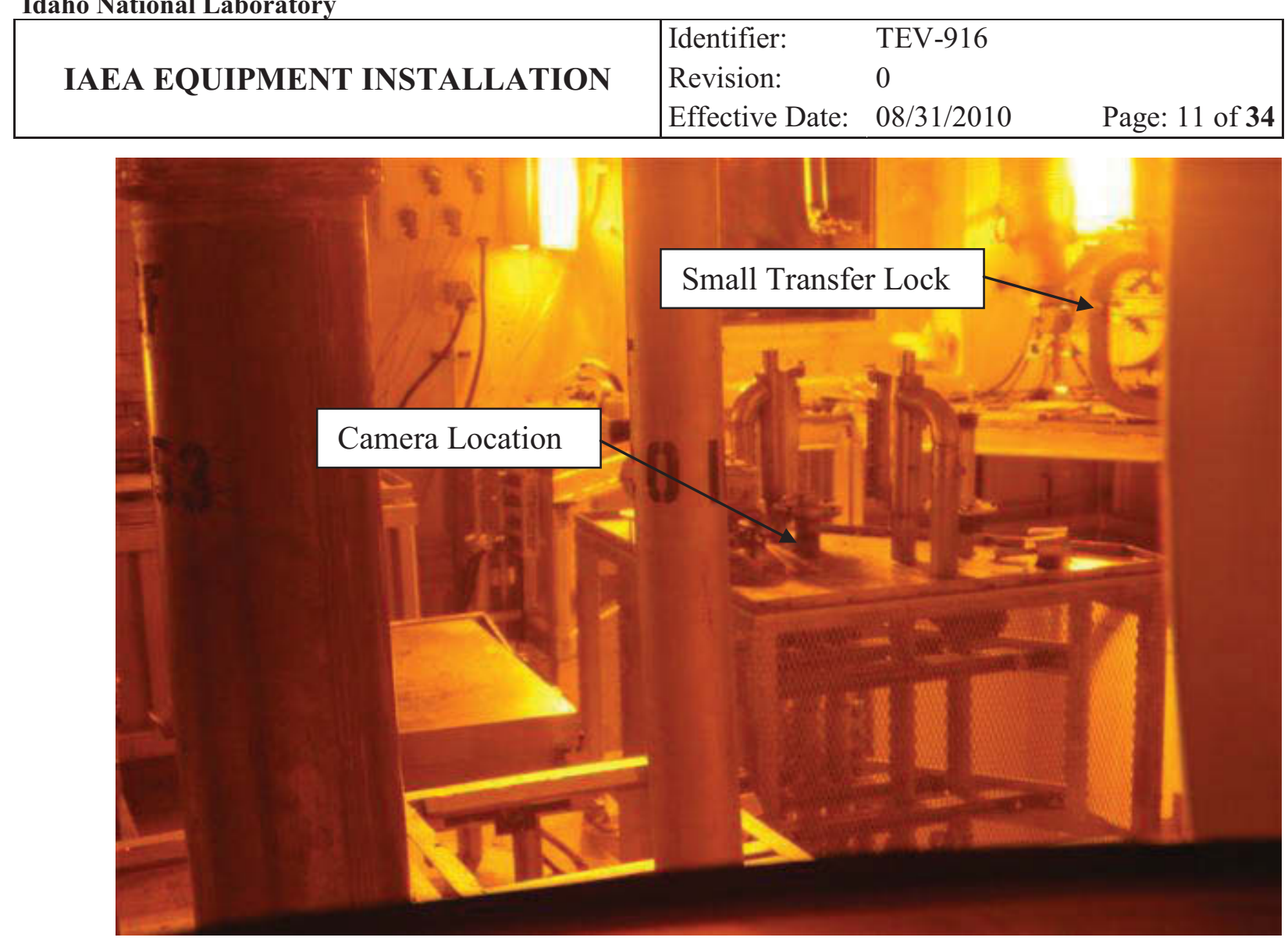

\section{Picture 3. Camera location for Alternative \#2.}

\section{Alternative \#3 - South Wall Feedthrough and Data Collection Station/Angle Bracket Camera Mount}

On the south interior wall of the air cell, above the man-entry door, is an angle bracket with six guide pins. This location is outside of the normal operational envelope for the air cell and can be accessed via the EMM and air cell crane. From this vantage point, a camera system (identical to alternatives \#1 and \#2) could view down to the Small Transfer Lock and limited obstructions would block visibility. The cameras could be mounted at this location with a simple system utilizing the guide pins. The system could rest at this location without any clamping mechanisms. See Picture 4 for the camera location of this alternative. 


\section{IAEA EQUIPMENT INSTALLATION}

Identifier:

Revision:

Effective Date: $08 / 31 / 2010$
TEV-916

\section{0}

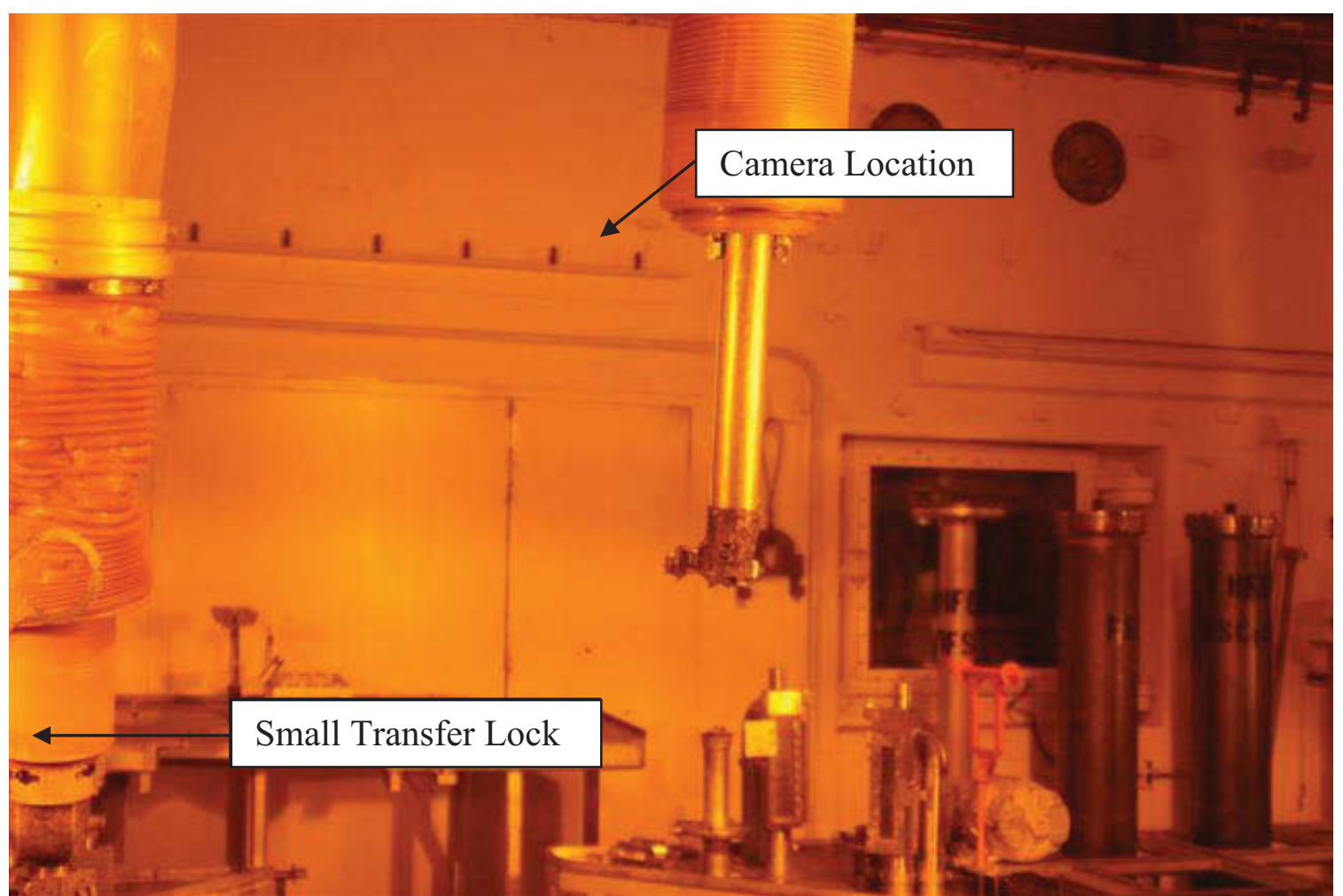

\section{Picture 4. Camera location for Alternative \#3.}

Feedthroughs 1.01 through 10.3 on the south wall are potential candidates for providing power and signal to the cameras. The data collection system (identical to that of alternative \#1 and \#2) could be placed adjacent to Window 1A (See Picture 5 below). 
IAEA EQUIPMENT INSTALLATION
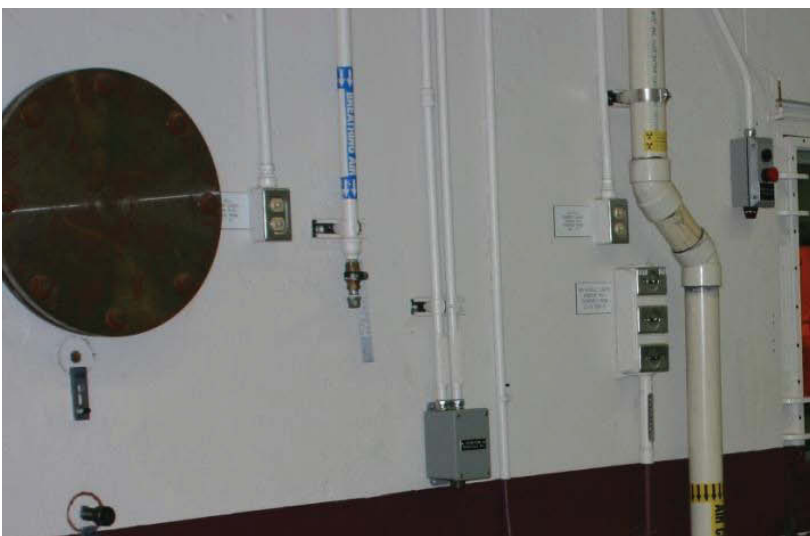

Identifier: $\quad$ TEV-916

Revision:

0

Effective Date: $08 / 31 / 2010$

Page: 13 of $\mathbf{3 4}$

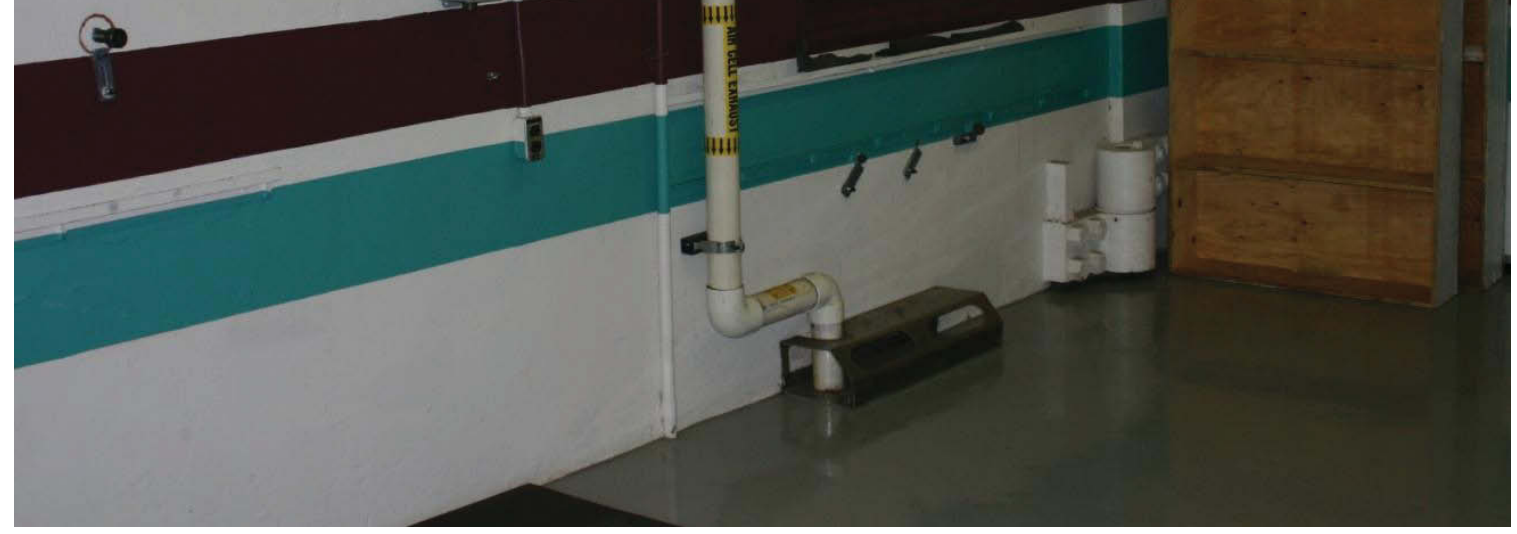

Picture 5. Data Collection System location for Alternative \#3. 
IAEA EQUIPMENT INSTALLATION Identifier: Revision:

TEV-916

Effective Date: $08 / 31 / 2010$

Page: 14 of 34

Alternative \#4 - North Wall Feedthrough and Data Collection Station/Window 8 A Bracket Camera Mount

Operations at Window 8A are currently suspended and the manipulators have been removed. A camera system could be mounted on the structure in front of this window at the location shown in Picture 6.

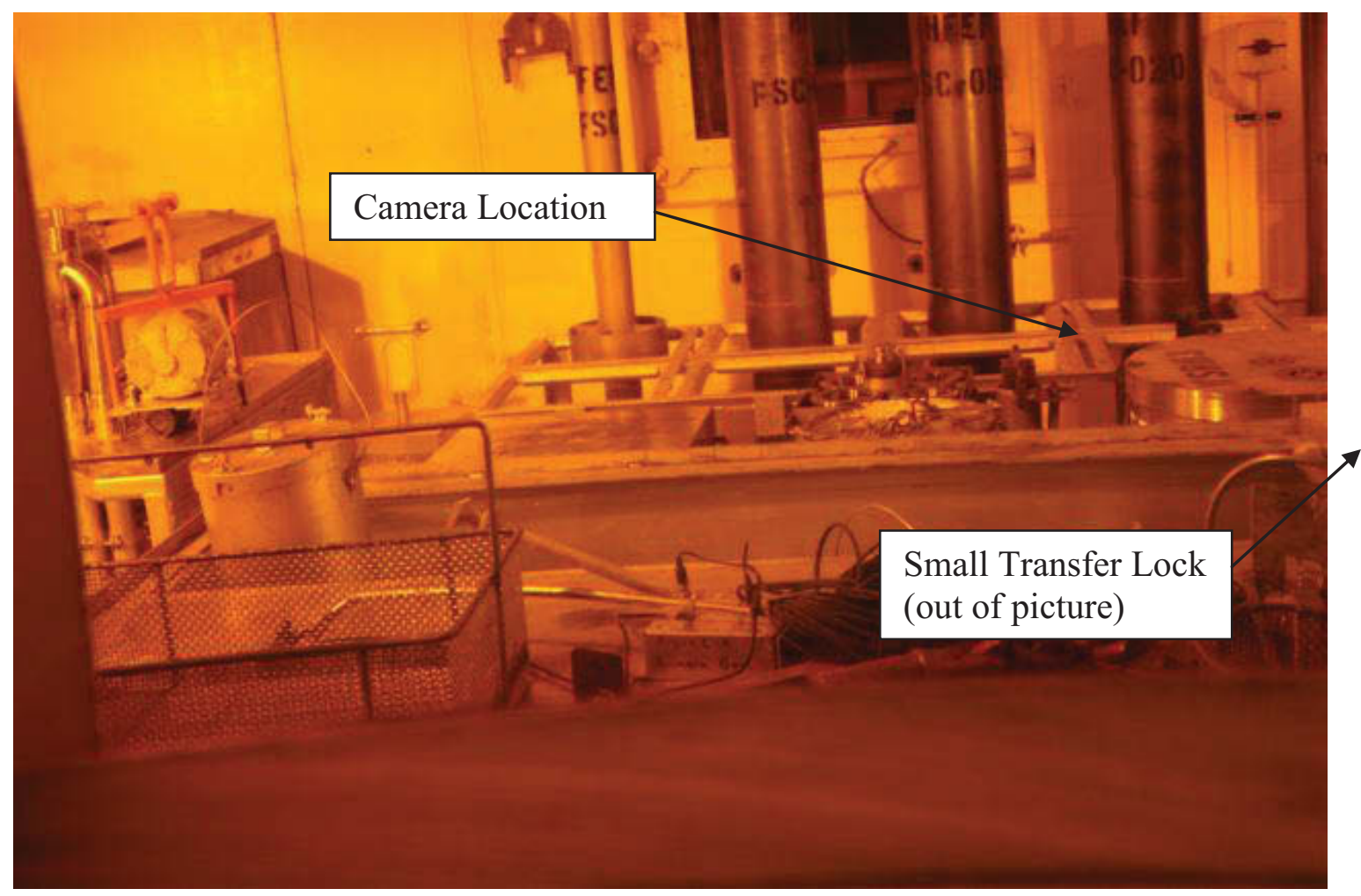

Picture 6. Camera location for Alternative \#4 (viewed from south wall).

Feedthroughs 7.01 through 7.06 on the north wall are potential candidates for providing power and signal to the cameras. The data collection system (identical to that of alternatives \#1, \#2, and \#3) could be placed adjacent to Window 7A (See Picture 7 below). 


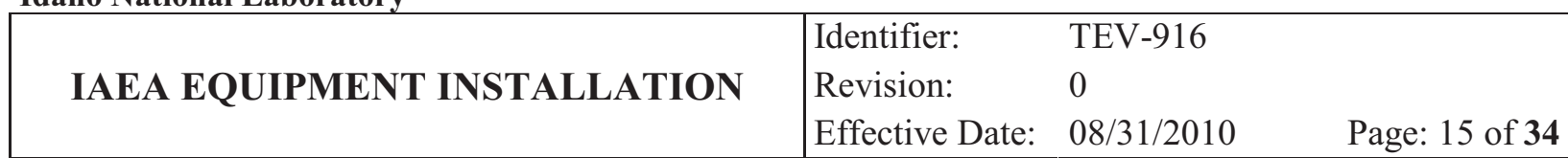

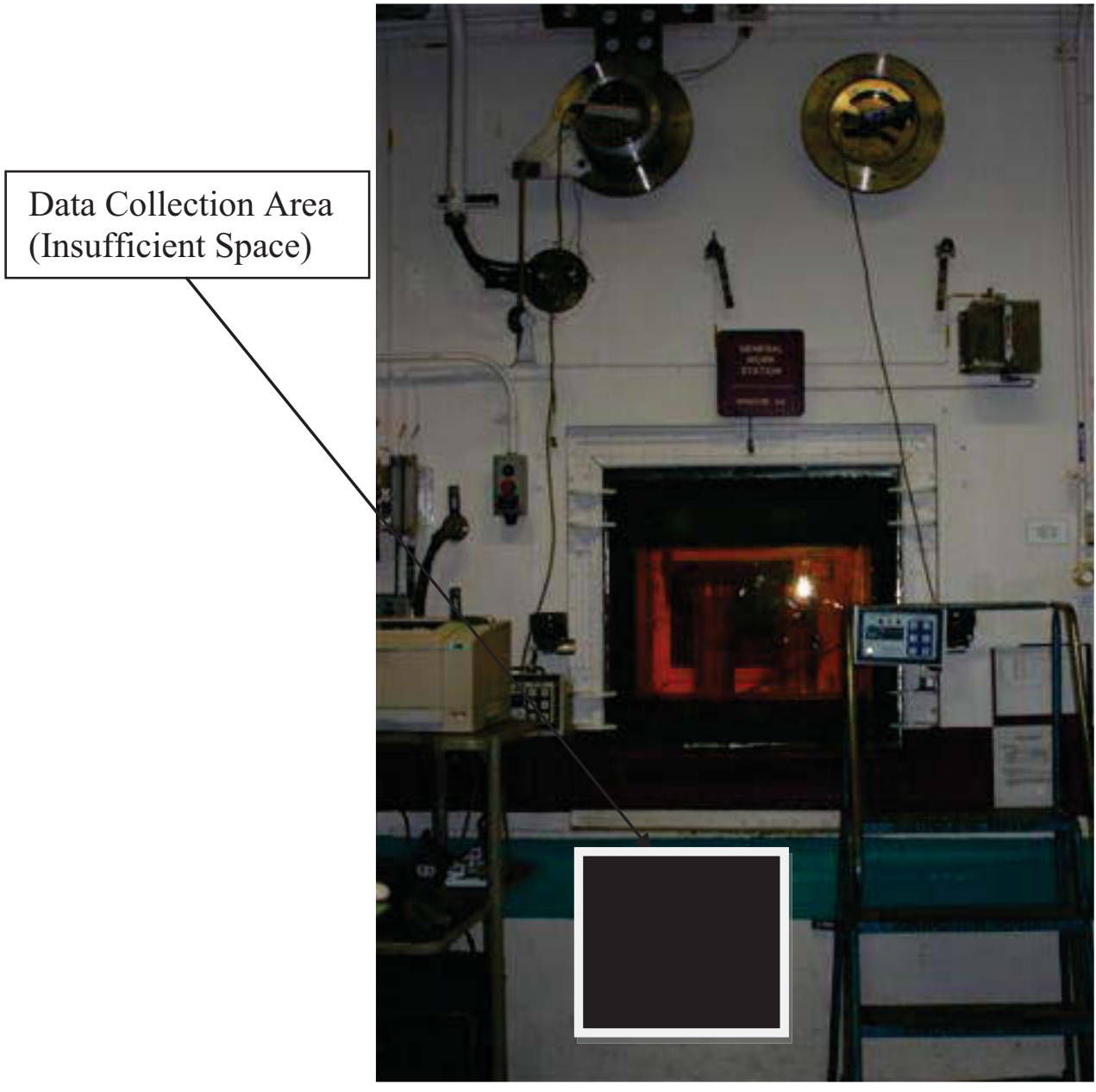

Picture 7. Data Collection System location for Alternative \#4. 


\section{IAEA EQUIPMENT INSTALLATION}

\begin{tabular}{lll} 
Identifier: & TEV-916 & \\
Revision: & 0 & \\
Effective Date: & $08 / 31 / 2010$ & Page: 16 of 34 \\
\hline
\end{tabular}

\section{Alternative \#5 - South Wall Feedthrough and Data Collection Station/Manipulator Feedthrough Camera Mount}

The manipulator feedthroughs at Window A1(11.1 and 11.2) and feedthrough 2.06 are potential candidates for use and could be transformed into a new feedthrough that incorporates a bubble confinement at the air cell boundary - allowing a camera system to reside within the feedthrough and to view into the air cell. The bubble is a thin semispherical transparent glass dome installed within the cell boundaries used as a contamination barrier. The feedthrough would be modified to accommodate the camera system and associated cabling. See Picture 8 for the location of the camera feedthroughs.

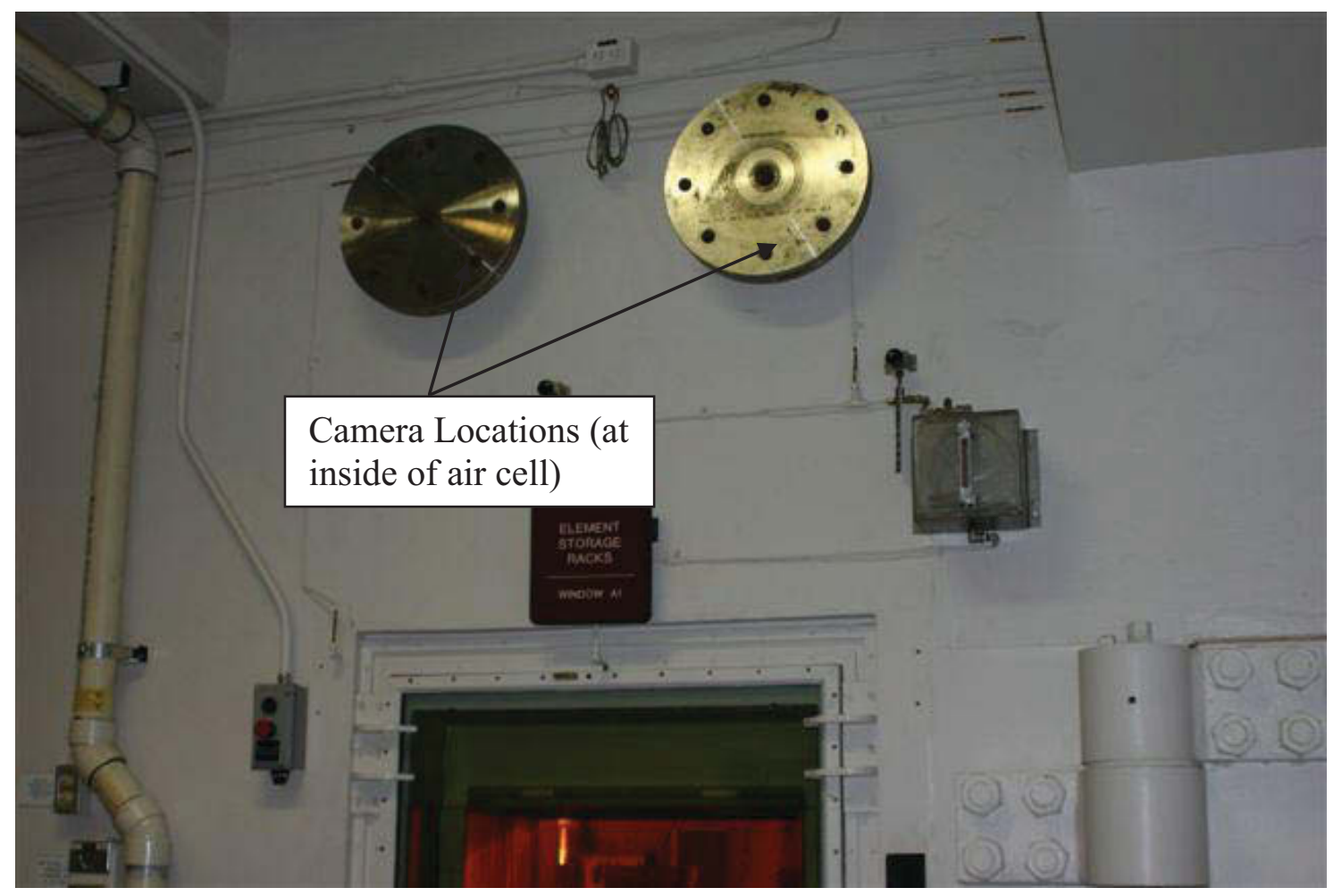

\section{Picture 8. Camera locations for Alternative \#5.}

No additional feedthroughs would be required for this option, and the data collection system location would be identical to that of alternative \#3 (see Picture 9 below). 
IAEA EQUIPMENT INSTALLATION

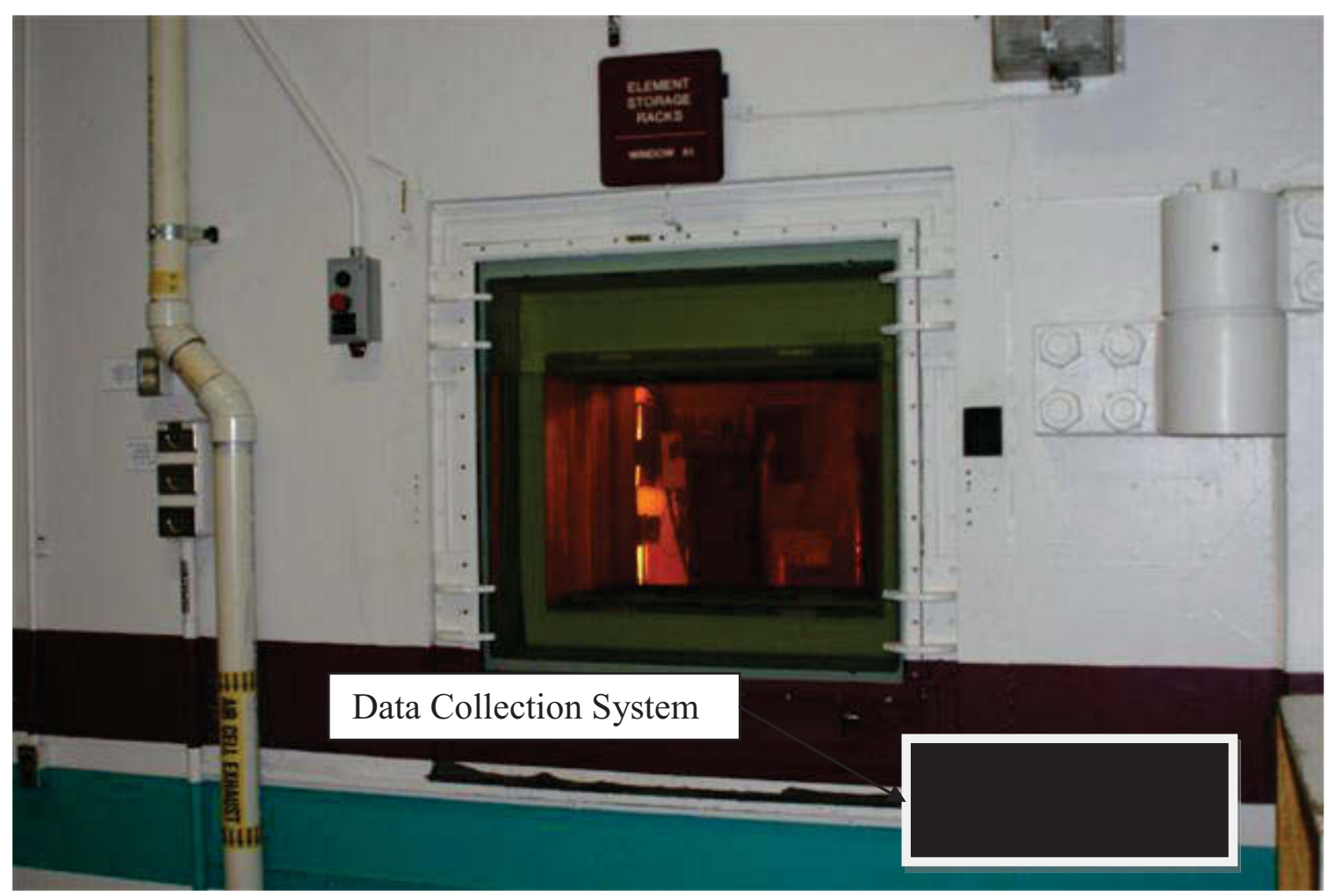

Picture 9. Data Collection System location for Alternative \#5.

Revision: $\quad 0$

Identifier: $\quad$ TEV-916 
IAEA EQUIPMENT INSTALLATION

$\begin{array}{lll}\text { Identifier: } & \text { TEV-916 } \\ \text { Revision: } & 0 & \\ \text { Effective Date: } & 08 / 31 / 2010 \quad \text { Page: } 18 \text { of } \mathbf{3 4}\end{array}$

Alternative \#6 - South Wall Feedthrough and Data Collection Station/Periscope Camera $\underline{\text { Mount }}$

The final alternative is to use the same feedthroughs identified in Alternative \#5 to install two new periscopes. These periscopes would be similar to those installed in penetrations 6.07 and 7.07 at Windows 6A and 7A. The camera system would be connected to a fixed periscope viewing the periscope image in the same manner that an operator would do. The periscope is capable of varied degrees of magnification and includes scan and rotate functions. The location of the camera would be completely outside of the air cell and no additional feedthroughs would be required, as all cabling is external to the air cell. The data collection system would reside in the same location as in Alternatives \#3 and \#5. See Picture 10 for a view of an existing periscope in the air cell.

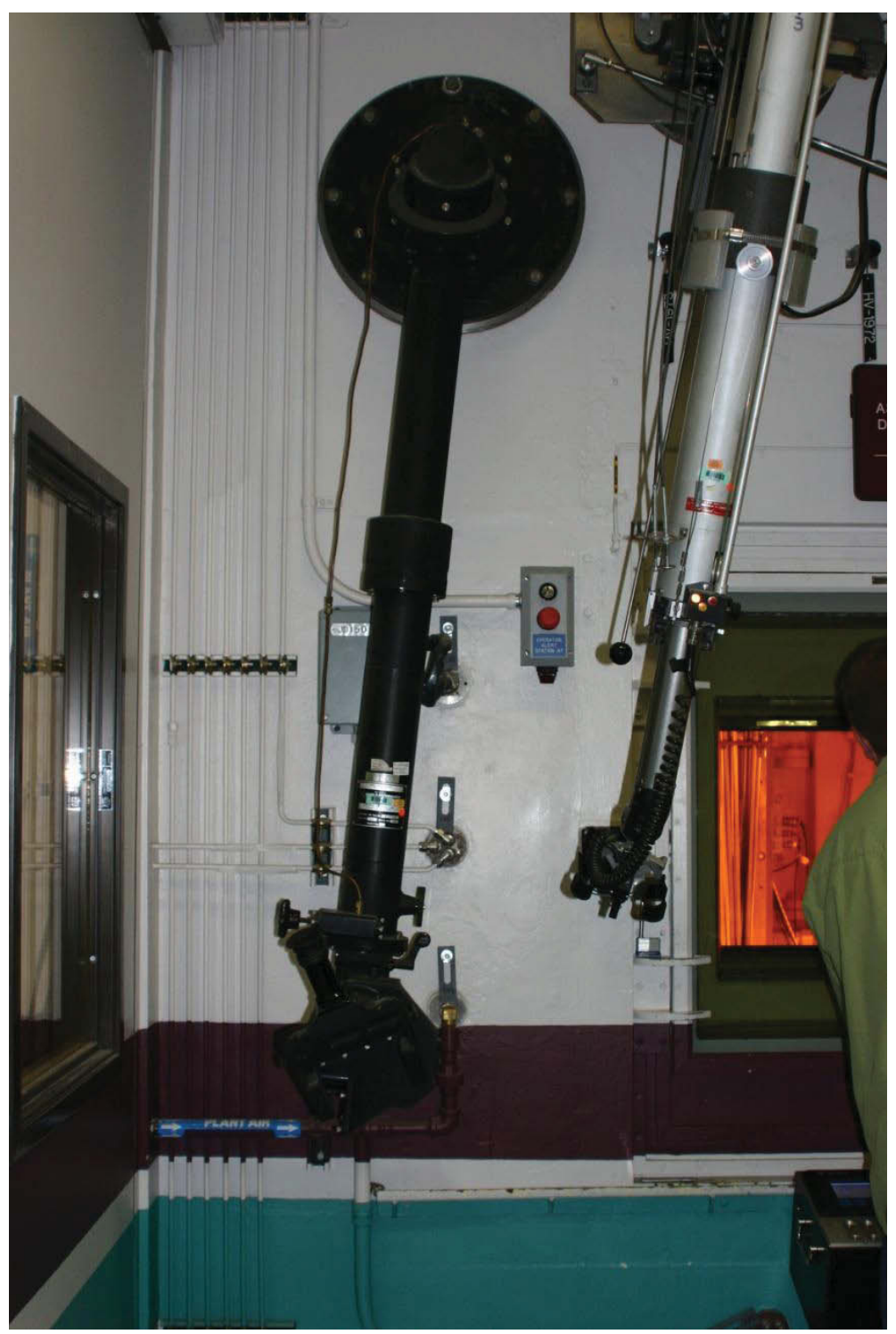

Picture 10. Periscope for Window 7A on the air cell. 


\begin{tabular}{l|lll|} 
IAEA EQUIPMENT INSTALLATION & $\begin{array}{l}\text { Identifier: } \\
\text { Revision: }\end{array}$ & 0 & \\
& Effective Date: & $08 / 31 / 2010$ & Page: 19 of 34 \\
\hline
\end{tabular}

\subsection{Elements/Functions of Proposed Solution(s)}

The first four alternatives are similar due to installing the camera within the air cell. The fifth and sixth alternatives are entirely different in the approach and don't involve mounting the camera within the air cell.

\subsection{Detailed Evaluation - Alternative \#1: North Wall Feedthrough and Data Collection Station/Table 9A NW Camera Mount}

\subsubsection{Advantages}

- Camera system location is in close proximity to the access port to be monitored

- Easy access to equipment with master-slave manipulators

- Cable management is simplified with use of North wall feedthroughs at window 9A.

\subsubsection{Disadvantages}

- Camera system location is in close proximity to the main inlet to the air cell - high traffic area within the air cell increases the potential for damage to equipment or interference with normal operations

- Could require vertical adjustment capability to accommodate equipment placed between the camera system and the access port additional hardware design and complexity

- The physical area around window 9A is congested with current equipment - additional equipment would create further congestion.

\subsection{Detailed Evaluation - Alternative \#2: North Wall Feedthrough and Data Collection Station/Table 9A SW Camera Mount}

\subsubsection{Advantages}

- Camera system location is in close proximity to the access port to be monitored

- Easy access to equipment with master-slave manipulators

- Cable management is simplified with use of North wall feedthroughs at window 9A. 


\begin{tabular}{l|lll|} 
IAEA EQUIPMENT INSTALLATION & $\begin{array}{l}\text { Identifier: } \\
\text { Revision: }\end{array}$ & 0 \\
& Effective Date: & $08 / 31 / 2010 \quad$ Page: 20 of $\mathbf{3 4}$ \\
\hline
\end{tabular}

\subsubsection{Disadvantages}

- Camera system location is in close proximity to the main inlet to the air cell - high traffic area within the air cell increases the potential for damage to equipment or interference with normal operations

- Could require vertical adjustment capability to accommodate equipment placed between the camera system and the access port additional hardware design and complexity

- $\quad$ The physical area around window 9A is congested with current equipment - additional equipment would create further congestion.

\subsection{Detailed Evaluation - Alternative \#3: South Wall Feedthrough and Data Collection Station/Angle Bracket Camera Mount}

\subsubsection{Advantages}

- Camera system location is high above the cell floor against the south wall and provides good perspective of air cell

- Camera system location is away from primary work areas and will not require movement to accommodate other work activities

- Camera system location is away from primary work area and has minimal exposure to damage from other equipment

- Convenient angle bracket with guide pins requires simplistic design features for mounting - less complex and less cost

- Resting location for the cables are optimal - completely out of the primary work zone

- The south wall is not in use and is an optimal location for a data collection station

- Because of the vertical height of the mounting, a pan \& tilt camera mount would be sufficient for providing optical viewing the cell. A vertical drive camera system would not be necessary.

\subsubsection{Disadvantages}

- Requires a long "pig tail" cable to accommodate movement of equipment to north side of air cell for any adjustments or repairs to the equipment by manipulators 


\subsection{Detailed Evaluation - Alternative \#4: North Wall Feedthrough and Data Collection Station/Window 8A Bracket Camera Mount}

\subsubsection{Advantages}

- Window 8A is currently only used to move items from window 9A to the west - no manipulators installed (acceptable place to place a camera)

\subsubsection{Disadvantages}

- The manipulators could be re-installed and the workspace could be reactivated - requiring the removal of the camera to another location

- Items are moved through the area on a frequent basis and create a potential for equipment to be damaged during operations

- Could require vertical adjustment capability to accommodate equipment placed between the camera system and the access port additional hardware design and complexity

- The physical area around window 9A is congested with current equipment - additional equipment would create further congestion.

\subsection{Detailed Evaluation - Alternative \#5: South Wall Feedthrough and Data Collection Station/Manipulator Feedthrough Camera Mount}

\subsubsection{Advantages}

- There are three primary feedthroughs normally used for master-slave manipulators that are not in use that could be used for a bubble-type camera mount

- Camera system location is high above the cell floor against the south wall and provides good perspective of air cell

- Camera system location is away from primary work areas and will not require movement to accommodate other work activities

- Camera system location is away from primary work area and has minimal exposure to damage from other equipment

- Inexpensive cameras may be used as the distance from radiological sources is maximized 


\begin{tabular}{l|lll|} 
IAEA EQUIPMENT INSTALLATION & $\begin{array}{l}\text { Identifier: } \\
\text { Revision: }\end{array}$ & 0 & \\
Effective Date: & $08 / 31 / 2010$ & Page: 22 of $\mathbf{3 4}$ \\
\hline
\end{tabular}

- Convenient manipulator feedthroughs have standard containment and procedures for installation and removal - less cost

- Resting location for the cables are optimal - completely out of the primary work zone

- Camera system is completely separated from the air cell - camera failures can be handled outside of the air cell confinement, thereby reducing cost

- The south wall is not in use and is an optimal location for a data collection station

\subsubsection{Disadvantages}

- $\quad$ Requires removal of shielding from the feedthrough for camera repair - handled procedurally

- Requires the design of a new feedthrough

- The camera is not physically located in the hot cell, which may be contrary to the Project's requirements and objectives

\subsection{Detailed Evaluation - Alternative \#6: South Wall Feedthrough and Data Collection Station/Periscope Camera Mount}

\subsubsection{Advantages}

- There are three primary feedthroughs normally used for master-slave manipulators that are not in use that could be used for a periscope

- Periscope is located high above the cell floor against the south wall and provides good perspective of air cell - camera is located completely outside of the air cell and can be accessed for repairs or adjustments

- Periscope and camera are located away from primary work areas and will not require movement to accommodate other work activities

- Periscope is located away from primary work area and has minimal exposure to damage from other equipment

- Periscopes have standard containment and procedures for installation and removal - less cost 


\begin{tabular}{|l|lll|}
\hline \multirow{2}{*}{ IAEA EQUIPMENT INSTALLATION } & Identifier: & TEV-916 & \\
& Revision: & 0 & \\
Effective Date: & $08 / 31 / 2010$ & Page: 23 of 34 \\
\hline
\end{tabular}

- No feedthroughs are required for the camera, as the camera is located completely outside of the air cell

- The south wall is not in use and is an optimal location for a data collection station

- If an existing approved periscope is used, it may preclude the requirement for updating the facility $\mathrm{SAR}$ - reduced cost

- Inexpensive cameras can be used, as radiation hardened equipment is not required

\subsubsection{Disadvantages}

- Additional cost to purchase and install a periscope into an existing manipulator feedthrough

- The camera is not physically located in the hot cell, which may be contrary to the Project's requirements and objectives

\section{RECOMMENDATION}

Based upon the engineering evaluation, it has become apparent that certain system characteristics are preferred. The north wall is clearly not the optimum location for a data collection system and camera placement in this location lends to damage and inconvenience for normal operations. The south wall has adequate feedthroughs, power, and is completely free of equipment and personnel to allow for a data collection system to be placed.

Alternative \#3 is the preferred option for an in-cell camera unit. This location is outside of the working envelope for current operations, has great visibility, and would require only a simplistic mounting hardware setup for installation. Cable management would be optimum for this location, and the data collection system could be located near the camera unit. The relative cost and schedule for this option are the best of all the alternatives, and the technical merit is high. Although the camera could be damaged incell (due to equipment or radiation), the relatively low cost for a replacement offsets the risk.

Alternative \#6, which would require the installation of one or two periscopes into existing master-slave feedthroughs, and the connection of camera systems to the optics of the periscopes, is the preferred solution from a technical perspective. This solution would allow the camera system to be located completely outside of the air cell, and no air cell feedthroughs would have to be modified to accommodate cabling. Repair costs would be minor, as the camera is easily accessible. However, this option would be the most expensive and could not be accomplished within the required timeline. 


\section{IAEA EQUIPMENT INSTALLATION}

$\begin{array}{lll}\text { Identifier: } & \text { TEV-916 } \\ \text { Revision: } & 0 \\ \text { Effective Date: } & 08 / 31 / 2010\end{array}$

Alternative \#5, which includes a modification to a master-slave manipulator feedthrough to incorporate a clear bubble confinement barrier and shield plug, is the second best technical option. Again, the camera is outside of the air cell and can be easily accessed for maintenance and repair. With this option, one feedthrough must be modified, and all cabling is routed through the main feeedthrough shell. This option, however, would be more expensive than Alternative \#3.

Alternatives 1, 2, and 4 should not be considered, based on the working envelope within the air cell, the restricted physical space on the outside of the north wall, and the added complexity to equipment to accommodate items being moved in front of the cameras.

\section{IMPLEMENTATION, SCHEDULE \& COST $^{1}$}

Implementation of the recommendation will follow the general path for design and fabrication of engineered equipment. Following is a schedule for the engineering effort:

\footnotetext{
${ }^{1}$ Following cost estimate is a rough order of magnitude estimate. The Cost Estimating Department should be consulted to create a formal cost estimate before work is conducted. This ROM estimate is based on high level requirements and general engineering experience.
} 


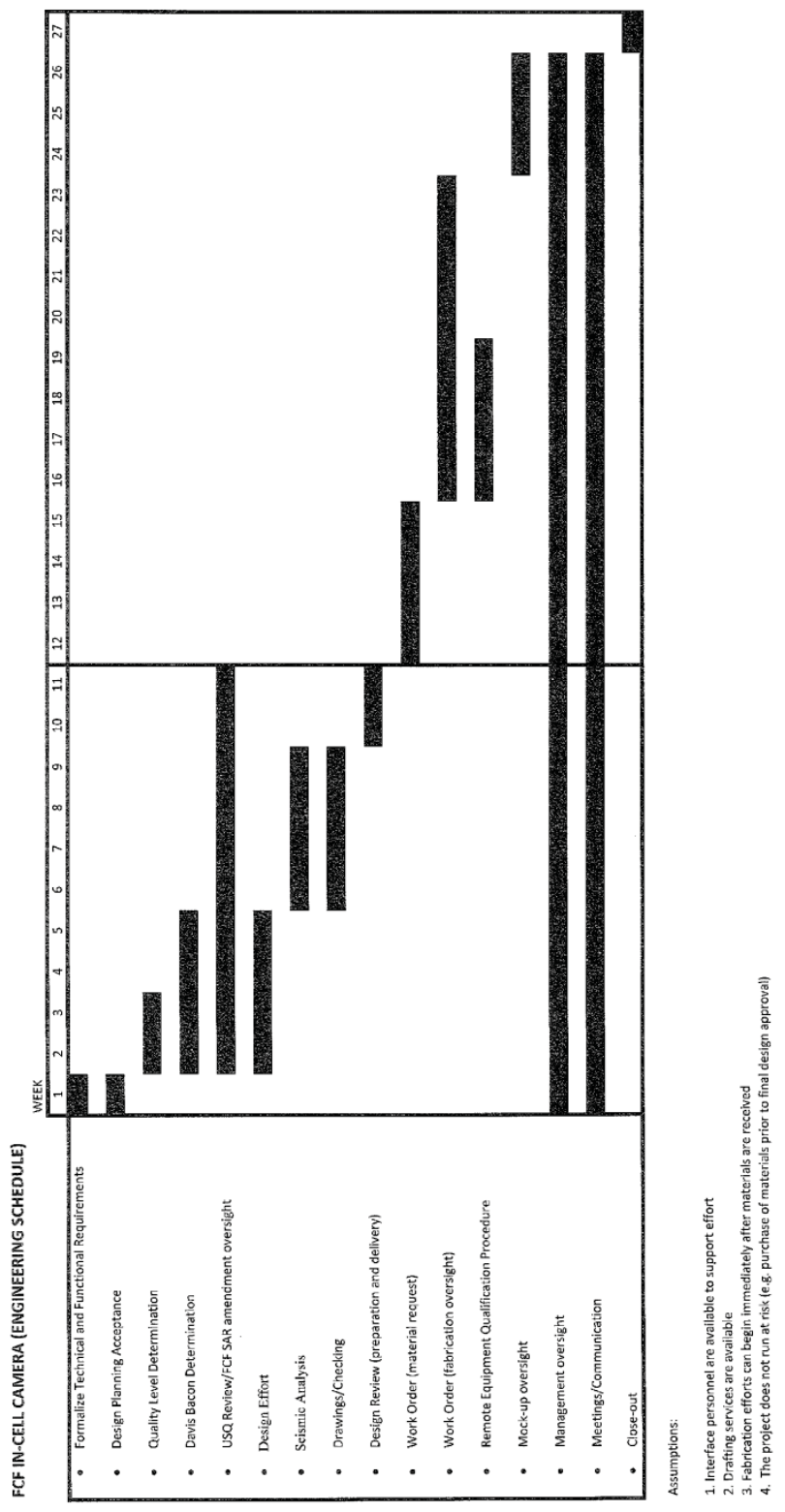

Following are the anticipated engineering hours to support the effort:

- Formalize Technical and Functional Requirements

- Mechanical - weight, range of operation, materials

8 hours

- Electrical - wiring, voltage/amps, connector specs

8 hours

- Software - duration, quality, format

8 hours

- Design Planning Acceptance

8 hours

- Quality Level Determination

4 hours

- Davis Bacon Determination

4 hours 


\section{IAEA EQUIPMENT INSTALLATION}

$\begin{array}{lll}\text { Identifier: } & \text { TEV-916 } \\ \text { Revision: } & 0 \\ \text { Effective Date: } & \text { 08/31/2010 }\end{array}$

Page: 26 of $\mathbf{3 4}$

- USQ Review/FCF SAR amendment oversight

24 hours

- Seismic/Structural Analysis (Camera stand)

40 hours

- Design Effort (Mechanical, Electrical, Software)

○ Mechanical

60 hours

- Structural

- Adjustment

- Connections/master-slave, EM crane

○ Electrical

60 hours

- Feedthrough design

- Connections to camera stand

- Software (Data Acquisition)

32 hours

- Programming

- Drawings/Checking

- Mechanical

- Camera Stand - 4 sheets

- Feedthrough - 4 sheets

- Electrical (One-line diagram) - 6 sheets

- Camera - pan/tilt/zoom control

- Stand adjustment control

- Single-line diagram

- Cable/connection diagram

- Electrical cabinet

- Design Review (preparation and delivery)

- Work Order (material request and fabrication oversight)

- Mechanical

- Electrical

- Software (Data Acquisition)

- Remote Equipment Qualification Procedure/Mock-up oversight

- Management oversight

- Meetings/Communication

- Package close-out
80 hours

80 hours

120 hours
40 hours

40 hours
80 hours

30 hours

24 hours

8 hours

Total Man-hours $=758$

Rate $=\$ 125 /$ hour

Cost $=\$ 94,750$

Assumptions:

1. Feedthrough design does not require new shielding analysis

2. Feedthrough is a modification of an existing design 
IAEA EQUIPMENT INSTALLATION
Identifier: $\quad$ TEV-916

Revision: $\quad 0$

Effective Date: $08 / 31 / 2010$

Page: 27 of $\mathbf{3 4}$

3. Data Acquisition system requires minimal programming

4. Costs do not include operations/technician time for installation of equipment

5. Costs do not include purchasing or fabrication costs

6. Costs do not include ALARA review for feedthrough installation

\section{Equipment (Rough Order of Magnitude) Estimate:}

- Costs for installation of feedthrough are approximately $\$ 50,000$ (based on prior department experience)

- Cost for radiation hardened camera equipment (or inexpensive camera system with external radiation shielding) is approximately $\$ 30,000^{2}$ (based on existing equipment in MFC hot cell)

- Cost for data acquisition system is approximately $\$ 20,000$ (based on engineering judgment)

- Cost for raw materials to fabricate camera mount and feedthrough is approximately $\$ 5,000$ (based on engineering judgment)

- Cost for fabrication is approximately $\$ 15,000$ (based on 1 machinist at $\$ 100 / \mathrm{hr}$ for 150 hours)

\section{Total estimated cost:}

Engineering - $\$ 95,000$

Equipment (Materials/Fabrication/Installation) - \$120,000

Total (excluding project management and extended review costs) $=\$ \mathbf{2 1 5 , 0 0 0}$

\footnotetext{
${ }^{2}$ Estimate is for one camera (fully radiation hardened). See Appendix A for relative camera costs.
} 
IAEA EQUIPMENT INSTALLATION

\section{CONCLUSIONS}

Based upon the technical, cost, and schedule requirements for the IAEA Equipment Installation project, the best option is to locate a set of radiation hardened cameras in the air cell on the inside of the south wall above the man entry door. The data acquisition system should be placed on the south wall of the air cell. Modifications to the feedthroughs, fabrication of the equipment, and receipt of the camera, data acquisition system can all be accomplished by an early 2011 target date, provided activities begin immediately.

\section{APPENDIXES}

Appendix A, Vendor Datasheets/INL Drawings for Pre-Conceptual Equipment 


\begin{tabular}{|c|lll|}
\hline \multirow{2}{*}{ IAEA EQUIPMENT INSTALLATION } & Identifier: & TEV-916 & \\
& Revision: & 0 & \\
Effective Date: & $08 / 31 / 2010$ & Page: 29 of 34 \\
\hline
\end{tabular}

\section{Appendix A}

\section{Vendor Datasheets/INL Drawings for Pre-Conceptual Equipment}

Note: The following vendor data/INL drawings are provided for informational purposes only and are based on high-level discussions with the Project Manager-the selection of equipment is pre-conceptual in nature. No engineering calculations or analysis has been conducted to select the proper equipment. Formal Technical and Functional Requirements have not been developed. 
IAEA EQUIPMENT INSTALLATION Identifier: TEV-916 Revision:

0 Effective Date: $08 / 31 / 2010$ Page: 30 of $\mathbf{3 4}$

\section{Appendix A - Camera Drive System}

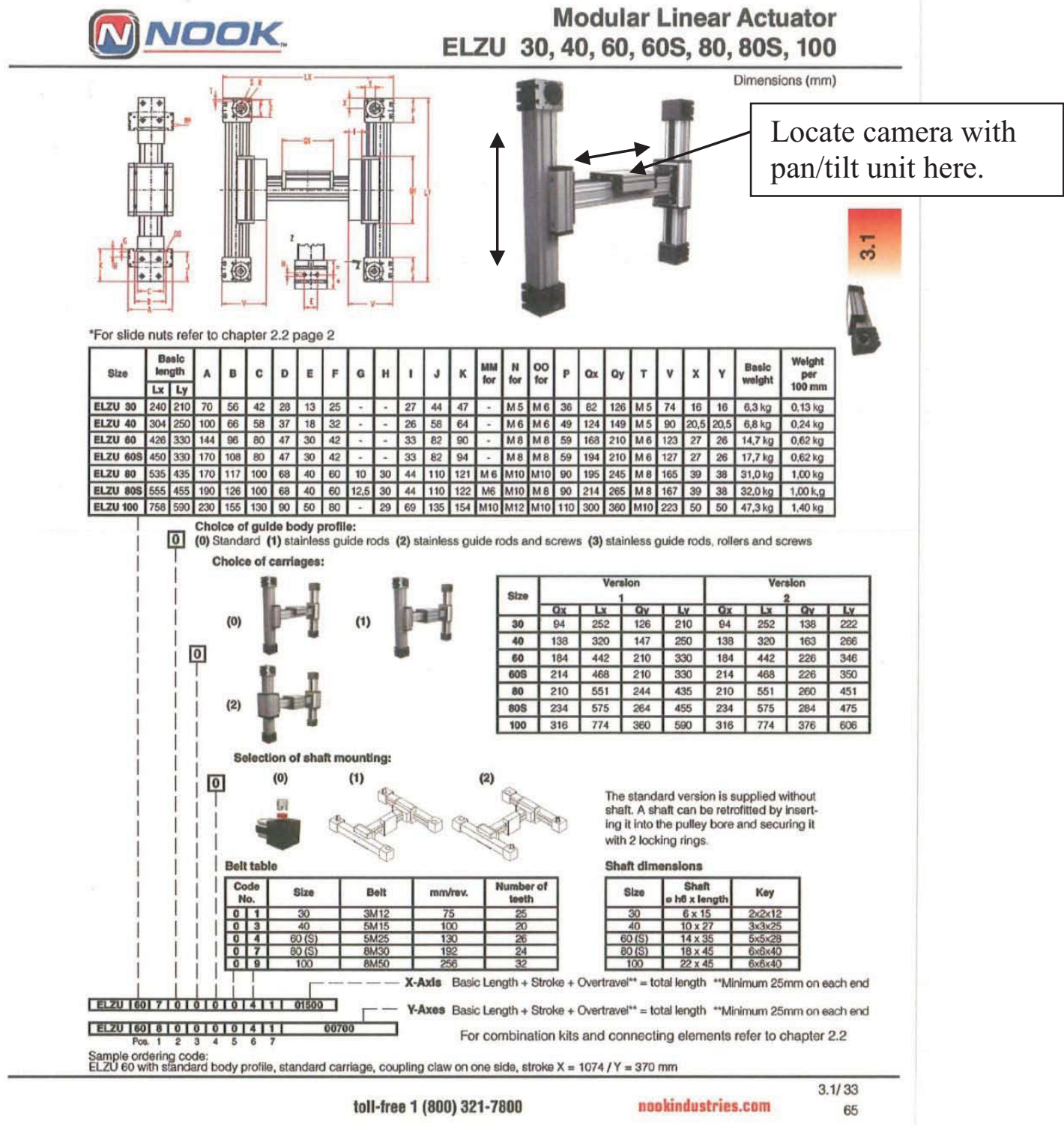

2-axis drive system that provides camera positioning in vertical and horizontal directions. Camera pan/tilt would be mounted to drive on horizontal member. System is shown for conceptual purposes only. Engineering effort required to determine exact requirements, loadings, and motion requirements. Custom equipment will most likely be necessary. 
IAEA EQUIPMENT INSTALLATION
Identifier: Revision: Effective Date: $08 / 31 / 2010$

TEV-916

0
Appendix A - Feedthrough Equipment

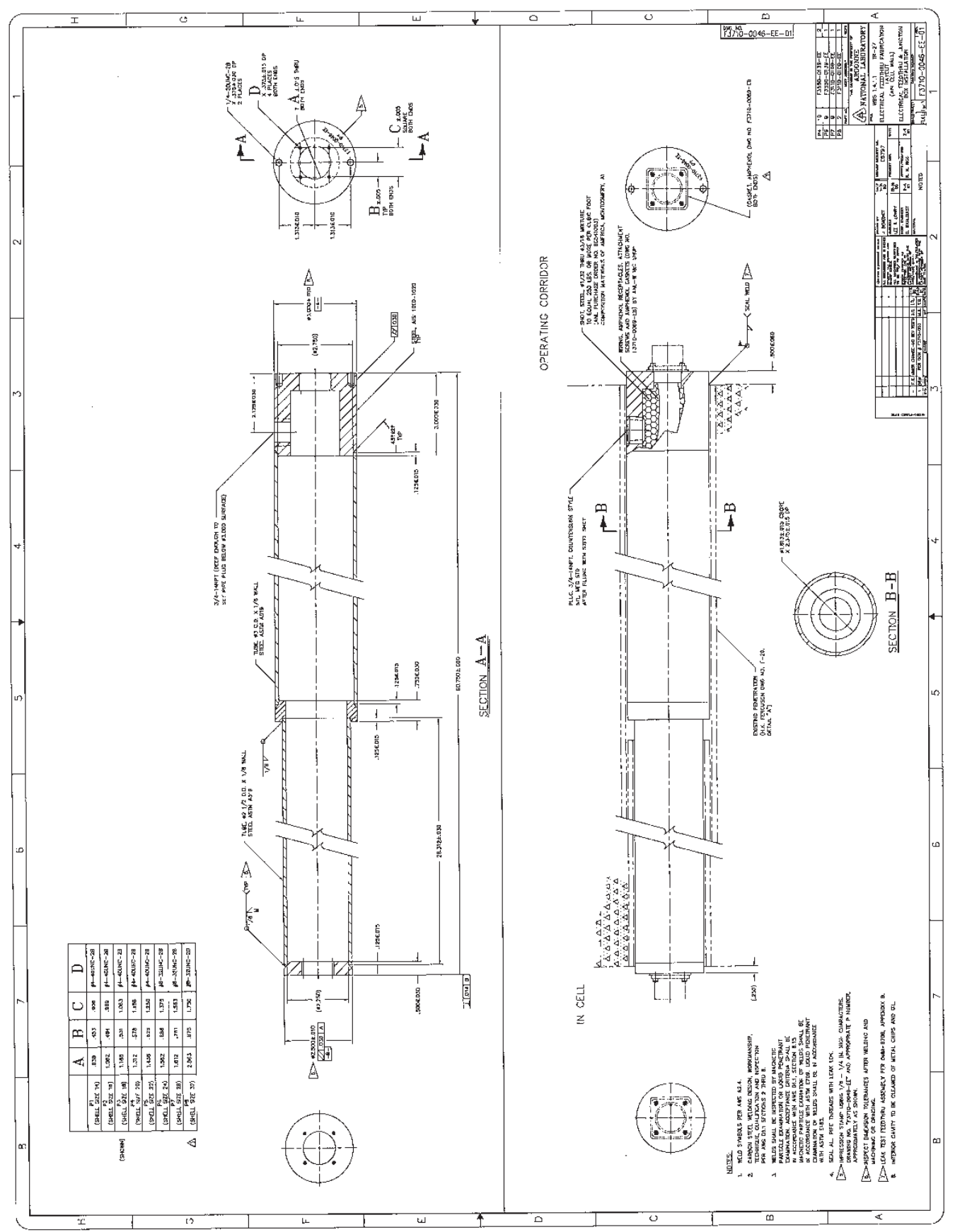

INL feedthrough used on FCF Air Cell. Feedthrough to be modified to accommodate power and signal requirements. Feedthrough could be enlarged and use master-slave manipulator cell penetration. 
IAEA EQUIPMENT INSTALLATION Identifier: TEV-916 Revision:

0 Effective Date: $08 / 31 / 2010$

\section{Appendix A - Camera/Data Acquisition Equipment}

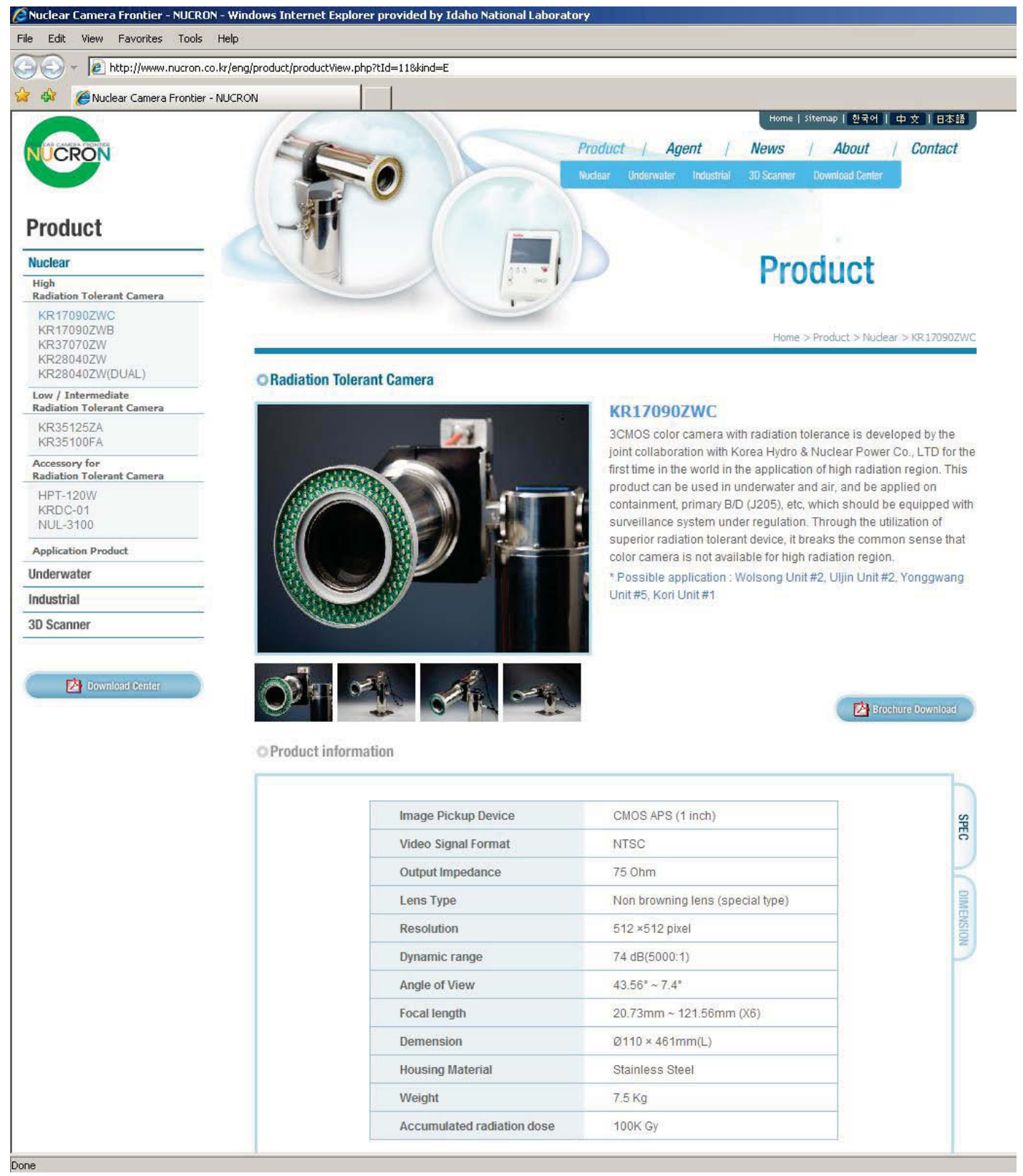

Radiation hardened camera with integrated pan/tilt unit. Outstanding questions that must be resolved prior to selection of the camera include:

- Black/white video sufficient, or is color video required?

- Spoofing $^{3}$ - required in-cell or out of cell?

${ }^{3}$ Spoofing is defined as the creation of a digital feedback loop that constantly shows an operator or recording device a still image that masks actual activities taking place. 
IAEA EQUIPMENT INSTALLATION $\begin{array}{ll}\text { Identifier: } & \text { TEV-916 } \\ \text { Revision: } & 0 \\ \text { Effective Date: } & 08 / 31 / 2010\end{array}$

Page: 33 of 34

- How much storage is required and what media type? Can the data acquisition record only if it detects a difference in the pixel orientation - thus saving data storage space?

- Normal or non-browning lens (dependent on duration of camera in-cell)?

Types of cabling to the camera (makes a difference on how far the camera can be from the feedthrough and how much data/resolution can be transmitted to the data acquisition system):

- Coax

- Twisted Pair

- USB2

- FireWire

- Ethernet

- GigE

The type of sensor technology within the camera is a major factor in the life of the unit. Following are lifetime estimates (based on engineering experience at INL), as well as comparative costs for the cameras ${ }^{4}$ :

- Closed Circuit Display (CCD) - 100 R to 2,000 R [\$300-\$1,200]

- Vacuum Tube $-1,000,000 \mathrm{R}$ to $10,000,000 \mathrm{R}[\$ 7,000]^{\mathbf{5}}$

- $\mathrm{CMOS}-5,000 \mathrm{R}$ to $10,000 \mathrm{R}[\$ 2,000-\$ 4,000]$

- $\mathrm{CID}-3,000,000 \mathrm{R}[\$ 7,000]$

The inexpensive camera life could be extended by incorporating shielding around the camera. Costs for shielding is relatively inexpensive and would extend the life of the camera considerably. Engineering effort for each of the different types of cameras is roughly equivalent. Assuming the radiation level within the air cell is $1 \mathrm{R} / \mathrm{hr}$, and the camera is exposed to this level 24 hours per day, the cameras would last approximately as follows ${ }^{6}$ :

CCD:

$$
(2,000 \mathrm{R}) /(1 \mathrm{R} / \mathrm{hr})=2,000 \text { hours }=(2,000 \text { hours })(1 \mathrm{day} / 24 \mathrm{hr})=83 \text { days }
$$

Vacuum Tube:

$(10,000,000 \mathrm{R}) /(1 \mathrm{R} / \mathrm{hr})=10,000,000$ hours $=(10,000,000$ hours $)(1 \mathrm{day} / 24 \mathrm{hr})=$ 41,667 days $=1,141$ years

\footnotetext{
${ }^{4}$ Excludes lens, pan/tilt unit, cabling, etc. - only basic camera unit cost.

${ }^{5}$ Equipment is difficult to obtain. There may no longer be units made within the United States of America.

${ }^{6}$ Actual radiation levels within the air cell vary dramatically, but can range from $5 \mathrm{R} / \mathrm{hr}$ to $940 \mathrm{R} / \mathrm{hr}-$ based on PWS No. FCF-PWS-13268. Note that camera lenses would brown before the sensor technology failure.
} 
IAEA EQUIPMENT INSTALLATION

CMOS:
Identifier: TEV-916

Revision: $\quad 0$

Effective Date: 08/31/2010

$(3,000,000 \mathrm{R}) /(1 \mathrm{R} / \mathrm{hr})=3,000,000$ hours $=(3,000,000$ hours $)(1 \mathrm{day} / 24 \mathrm{hr})=$ 125000 days $=342.5$ years

Based on the range of the radiation levels within the air cell, preference should be given to either CMOS technology, with the potential addition of external radiation shielding, or CID technology. Preference should also be given to camera units that remove as much of the electronic hardware away from the lens area as possible, to permit shielding of electronics. 